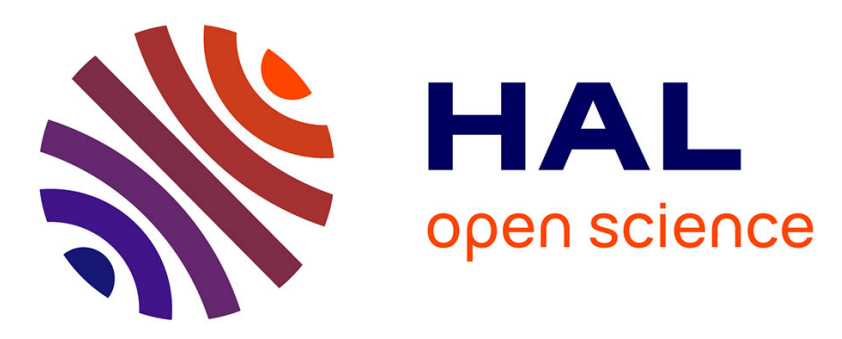

\title{
Molecular dynamics simulation of the effect of $\mathrm{pH}$ on the adsorption of rhodamine laser dyes on $\mathrm{TiO} 2$ hydroxylated surfaces
}

Said Hamad, Juan Ramon Sanchez Valencia, Angel Barranco, Jose Antonio Mejias, Agustin R González-Elipe

\section{To cite this version:}

Said Hamad, Juan Ramon Sanchez Valencia, Angel Barranco, Jose Antonio Mejias, Agustin R González-Elipe. Molecular dynamics simulation of the effect of $\mathrm{pH}$ on the adsorption of rhodamine laser dyes on TiO2 hydroxylated surfaces. Molecular Simulation, 2009, 35 (12-13), pp.1140-1151. 10.1080/08927020903108083 . hal-00530458

\section{HAL Id: hal-00530458 https://hal.science/hal-00530458}

Submitted on 29 Oct 2010

HAL is a multi-disciplinary open access archive for the deposit and dissemination of scientific research documents, whether they are published or not. The documents may come from teaching and research institutions in France or abroad, or from public or private research centers.
L'archive ouverte pluridisciplinaire HAL, est destinée au dépôt et à la diffusion de documents scientifiques de niveau recherche, publiés ou non, émanant des établissements d'enseignement et de recherche français ou étrangers, des laboratoires publics ou privés. 


\section{Molecular Simulation}

Journal of

Experimental Nanoscience

\section{Molecular dynamics simulation of the effect of pH on the adsorption of rhodamine laser dyes on TiO2 hydroxylated surfaces}

\begin{tabular}{|r|l|}
\hline Journal: & Molecular Simulation/Journal of Experimental Nanoscience \\
\hline Manuscript ID: & GMOS-2009-0023.R1 \\
\hline Journal: & Molecular Simulation \\
\hline Date Submitted by the \\
Author: & 18-Apr-2009 \\
\hline Keyworde List of Authors: & $\begin{array}{l}\text { Hamad, Said; Institute of Materials Science of Seville, CSIC - } \\
\text { University of Seville; University Pablo de Olavide, Department for } \\
\text { physical, chemical and natural systems } \\
\text { Sanchez Valencia, Juan Ramon; Institute of Materials Science of } \\
\text { Seville, CSIC - University of Seville } \\
\text { Barranco, Angel; Institute of Materials Science of Seville, CSIC - } \\
\text { University of Seville } \\
\text { Mejias, Jose Antonio; University Pablo de Olavide, Department for } \\
\text { physical, chemical and natural systems } \\
\text { González-Elipe, Agustin; Institute of Materials Science of Seville, } \\
\text { CSIC - University of Seville }\end{array}$ \\
\hline \hline Rhodamine, adsorption, TiO2, anatase, simulation \\
\hline
\end{tabular}

\section{SCHOLARONE Manuscripts}




\section{Molecular dynamics simulation of the effect of $\mathrm{pH}$ on the adsorption of rhodamine laser dyes on $\mathrm{TiO}_{2}$ hydroxylated surfaces}

Said Hamad ${ }^{1,2 *}$, Juan Ramon Sanchez-Valencia ${ }^{1}$, Angel Barranco ${ }^{1}$, Jose Antonio Mejias ${ }^{2}$ and Agustin R. Gonzalez-Elipe ${ }^{1}$

1) Instituto de Ciencia de Materiales de Sevilla, CSIC-Universidad de Sevilla, Calle Américo Vespucio, nº 49, 41092, Seville, Spain.

2) University Pablo de Olavide, Department of Physical, Chemical and Natural Systems, Carretera de Utrera, km 1, Seville, Spain.

We have carried out a study of the adsorption, on the (101) surface of anatase $\mathrm{TiO}_{2}$, of two industrially relevant rhodamines molecules (rhodamine 6G and rhodamine 800) employing Molecular Dynamics. These theoretical studies have shown that Rhodamine 6G must adsorb on Deleted: surfaces under basic conditions. Moreover, the adsorption of this molecule shows a strong dependence upon the $\mathrm{pH}$ of the system, i.e. under basic conditions the adsorption energy is quite high, under neutral conditions the adsorption energy is lower, and under acidic conditions an even lower adsorption energy indicates that there must be very little adsorption under such conditions. By contrast, for rhodamine 800 there is little dependence of the adsorption energy upon the $\mathrm{pH}$, suggesting that the amount of adsorption of this molecules is little affected by this parameter. 
Keywords: Rhodamine, adsorption, $\mathrm{TiO}_{2}$, anatase, (101) surface, Molecular Dynamics, PZC.

1

2

3

4

5

6

7

8

9

10

11

12

13

14

15

16

17

18

19

20

21

22

23

24

25

26

27

28

29

33

34

35

36

37

38

39

40

41

42

43

44

45

46

47

48

49

50

51

52

53

54

55

56

57

58

59

60 


\section{Introduction}

Rhodamines are biocompatible, photostable and luminescent dye molecules, widely used for a large variety of applications including laser, probe molecule of surface states, solar cells, or surface coatings ${ }^{1-4}$. For the majority of these uses, the dye molecule has to be incorporated into a solid, a feature that has fostered both the development of new synthesis and processing methods of the final materials and the study of their optical and fluorescent behaviours. Thus, for example, it has been shown that rhodamine-G molecules can be easily incorporated within the interlayer space of silicates and other layered materials ${ }^{5-9}$. The incorporation of these molecules into sol-gel silica, mesoporous $\mathrm{TiO}_{2}$ thin films or into polymeric matrices has been also intended for the fabrication of optical components and devices ${ }^{10-13}$.

Recently, we have shown that R6G and R800 dye molecules can be incorporated within transparent and porous films of $\mathrm{TiO}_{2}$ or $\mathrm{Ta}_{2} \mathrm{O}_{5}$ prepared by glancing angle evaporation just by immersing the films into an aqueous solution of the two dye molecules in cationic form ${ }^{14}$. The incorporation of the dye molecules into the film was driven by the $\mathrm{pH}$ of their solution and, in the case of the R6G, explained by using the classical concepts of the point of zero charge (PZC) developed in the 1960's to account for the adsorption of ions on the surface of colloidal oxides ${ }^{15}$. The results represents a clear evidence for the importance of the interaction of the hydroxilated porous oxide surfaces with the cationic dye molecules during the absorption processes. In particular, we found that the R6G only starts to become incorporated within the pores of the films when the $\mathrm{pH}$ of the solution was approaching or was higher than the $\mathrm{PZC}$ of $\mathrm{TiO}_{2}$ (i.e., around 5.5 (refs. 14 and 15). The simplicity of the experimental method used for the preparation of these composite thin films has motivated the present theoretical work, where we account for the different effect of the $\mathrm{pH}$ and on the adsorption of $\mathrm{R} 6 \mathrm{G}$ and $\mathrm{R} 800$ on the surface of $\mathrm{TiO}_{2}$. For this purpose we present here a theoretical study by using Molecular Dynamics techniques to obtain 
information about the adsorption of these two dye molecules. The results obtained can be of relevance for the study of other types of composite materials consisting of dye molecules adsorbed on the surface of $\mathrm{TiO}_{2}$. A classical example in this respect is that of the Grätzel solar cells ${ }^{16,17}$. In this context, previous theoretical studies in the literature have dealt with the adsorption of $R u(I I)-$ polypyridyl dyes on the surface of an ideal $\mathrm{TiO}_{2}$ surface ${ }^{18}$. However, to our knowledge, no theoretical studies have been carried out to investigate the interaction of these or similar dye molecules with a hydroxylated surface of this oxide, taking into account the effect of $\mathrm{pH}$ on their adsorption. For the present study, we have used four different types of surfaces, on which to model the adsorption of the rhodamine molecules. The chosen models of surfaces provide a description of the adsorption on non-hydroxylated surfaces, as well as on surfaces under basic, neutral and acidic conditions.

\section{Computational details}

The first step in any Molecular Dynamics (MD) simulation is the compilation of an adequate set of interatomic potentials to model the system. Our experimental observations require the use of computational features which are somehow more complicated than those of usual MD simulations, since we need to model the influence of hydroxylation and $\mathrm{pH}$. $\mathrm{TiO}_{2}$ surfaces are usually modelled as clean, non-hydrated, non-hydroxilated surfaces, although there are some exceptions in literature ${ }^{23-27}$. The initial set of parameters used to model the $\mathrm{TiO}_{2}(101)$ anatase surface were taken from the modification that Predota et al. ${ }^{23,28}$ made of the Matsui and Akaogi potentials $^{29}$ to study (110) rutile hydroxylated surfaces. The parameters presented by Predota et al. ${ }^{23,28}$ were not optimised to model the hydroxylated (101) anatase surface, and when they were used to minimise the surface, we observed the rupture of $\mathrm{O}-\mathrm{H}$ bonds upon minimisation.

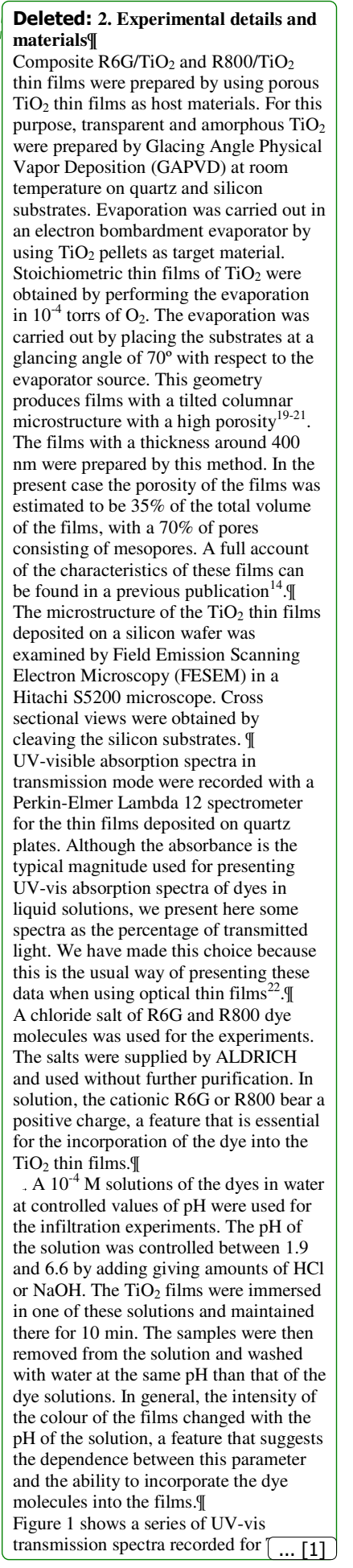


Therefore, some changes were introduced into the interatomic potentials to allow us to study of the hydroxylated (101) anatase surface. In order to have a reference to test the results of the changes of the interatomic potentials parameters, we carried out the optimisation of a hydroxylated (101) anatase surface with the Density Functional Theory (DFT), using the plane-wave-pseudopotential approach within the projector augmented wave method $(\mathrm{PAW})^{30}$, together with the Generalized Gradient Approximation (GGA) exchange correlation functional proposed by Perdew et al. ${ }^{31}$, as implemented in the Vienna Ab-initio Simulation Package (VASP) $4.6 \operatorname{code}^{32-34}$. A plane-wave cutoff energy of $400 \mathrm{eV}$ was used. The Ti (3s, 3p, 3d, 4s), O (2s, 2p) and H (1s) electrons were treated as valence states, while the remaining electrons were kept frozen as core states. The Brillouin-zone integrations were performed using Monkhorst-Pack grids ${ }^{35}$. The slab approximation was used to model the surface, with a $\mathrm{TiO}_{2}$ slab thickness of $20 \AA$, and a vacuum slab of $10 \AA$. The cell dimensions are $5.44 \AA \times 3.78 \AA ̊ \times 30.0 \AA$. The calculations were carried out by using a $(7 \times 7 \times 1)$ mesh, with which convergence in energy was achieved.

In order to get a good agreement with the geometries obtained with the DFT calculations, we made some modifications in the interatomic potentials. Since one of the requirements was the modelling of the O-H bonds at the surface (such as bonds 2-3 and 4-5 in Figure 1), we introduced a harmonic force between the $\mathrm{O}$ and $\mathrm{H}$ atoms of the surface hydroxyl groups of the form $\mathrm{E}=$ $1 / 2 \cdot \mathrm{k}_{1} \cdot\left(\mathrm{r}-\mathrm{r}_{\mathrm{o}}\right)^{2}$. The values of the parameters were: $\mathrm{k}_{1}=500.4 \mathrm{kcal} \mathrm{mol}{ }^{-1} / \AA^{2}$ and $\mathrm{r}_{\mathrm{o}}=0.95 \AA$. Another important parameter in the description of the surface is the harmonic force that predicts a correct value of the Ti-O-H angles such as the angles 1-2-3 and 1-4-5 in Figure 1. This force is of the form $\mathrm{E}=1 / 2 \cdot \mathrm{k}_{2} \cdot\left(\theta-\theta_{0}\right)^{2}$ where $\theta$ is the angle between the three atoms, $\theta_{0}$ is the equilibrium value of this

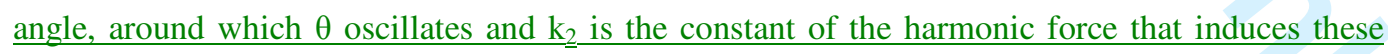
oscillations. For O-H groups connected to terminal Ti atoms we did not change the parameters, but 
parameters are $\mathrm{k}_{2}=14.136 \mathrm{kcal} \mathrm{mol}^{-1} \operatorname{rad}^{-2}$ and $\theta_{\mathrm{o}}=120^{\circ}$. The geometry of the hydroxylated (101) anatase surface obtained with this new set of interatomic potentials is in reasonable good agreement with that obtained with DFT calculations, as shown in Table 2. The larger disagreement, as expected, is found for the distance between atoms 5 and 11 , since they interact by a weak hydrogen bond, a situation which is difficult to model accurately using interatomic potentials.

To model the rhodamine molecules we have employed the DREIDING force field ${ }^{36}$, which was developed to predict structures and dynamics of organic, biological and main-group inorganic molecules. The van der Waals parameters of the DREIDING force field are taken from the Williams potentials ${ }^{37,38}$, including some modifications. The electrostatic charges were calculated with $a b$ initio calculations, by fitting the electrostatic potential at points selected according to the Merz-Singh-Kollman scheme ${ }^{39,40}$, as implemented in the program Gaussian $03^{41}$. The Becke three parameter hybrid functional $^{42}$ (B3LYP) was used to fit the atomic charges, together with a 6$31+\mathrm{G}^{*}$ basis set $\mathrm{SI}$ Table 1 and SI Table 2 show the atomic charges as well as the force type assignments. This level of theory has been previously used to study other dyes ${ }^{43}$. The DREIDING force field predicts an equilibrium angle of $\sim 40^{\circ}$ between the xanthene and phenyl moieties that form the rhodamine $6 \mathrm{G}$ molecule, whereas ab initio calculations predict that the planes of the two moieties lie perpendicular to each other. In order to predict correctly this angle of $90^{\circ}$, we included an additional torsional term in the force field. In DREIDING, the torsion interaction for two bonds (those between atoms IJ and KL) connected via a common bond JK takes the form, $E_{I J K L}=\frac{1}{2} V_{J K}\left\{1-\cos \left[n_{J K}\left(\varphi-\varphi_{J K}^{0}\right)\right]\right\}$

where $\varphi$ is the dihedral angle (angle between the IJK and JKL planes), $n_{J K}$ is the periodicity (an integer), $V_{J K}$ is the barrier for rotation (always positive), and $\varphi_{J K}^{0}$ is the equilibrium angle. We did 
not carried out a parameter fitting in order to obtain the value of the parameters needed to model correctly the angle between the two moieties. Instead, we introduced an additional term, taking the same parameters that describe the torsion of a dihedral resonance bond (bond order $=1.5$ ) involving two resonant atoms, namely $\mathrm{V}_{\mathrm{JK}}=25 \mathrm{kcal} / \mathrm{mol}, \mathrm{n}_{\mathrm{JK}}=2$, and changing the equilibrium angle from $\varphi_{J K}^{0}=180^{\circ}$ to $\varphi_{J K}^{0}=90^{\circ}$. This torsional force is only included to model the interaction between atoms C9 and C14 in Figure 2a. We checked the validity of this term by comparing the variation of the energy with respect to the rotation angle, this latter obtained with the interatomic potentials discussed and two ab initio methods: B3LYP/6-31+G* and MP2/6-31++G**. The results are shown in Figure 3. In the most critical region, between $90^{\circ}$ and $110^{\circ}$, the three methods predict essentially the same dependency with respect to the rotation. For angles higher than $110^{\circ}$ the less accurate methods (interatomic potentials and B3LYP/6-31+G*) predict a different change in energy than MP2/6-31++G**, although at $120^{\circ}$ the energy difference is still less than 3 $\mathrm{kcal} / \mathrm{mol}$. We can therefore consider that the DREIDING force field, with this additional term, predicts correctly the behaviour of rhodamine 6G. In the case of rhodamine 800 there is no need to include any additional terms, since the DREIDING force field describes it correctly. The van der Waals interaction between the rhodamine molecules and the surface are taken from the DREIDING force field. The existence of parameters to describe the interaction between the molecules and the $\mathrm{TiO}_{2}$ surface (which is not the case for other force fields such as AMBER or CHARMM) is the main reason why the DREIDING force field is used.

\begin{abstract}
All interatomic potentials based energy minimisations and Molecular Dynamics simulations have been performed with the GULP $\operatorname{code}^{44}$, at the high performance computing facilities of CSIC in Madrid. The timestep for the integration of the equations of motion is $1 \mathrm{fs}$. The systems are modelled in the canonical (NVT) ensemble, employing the Hoover thermostat, with a friction constant for the temperature bath of 0.1 , to maintain the temperature around $298^{\circ} \mathrm{C}$.
\end{abstract}




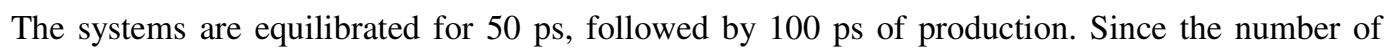
degrees of freedom associated with the motion of the rhodamine molecules is relatively small, there is no need to perform very long simulations to sample the most relevant region of the phase space.

The ab initio calculations (using Gaussian03 and VASP) have been carried out in the Finis Terrae supercomputer, in Santiago de Compostela, Spain.

Formatted: English U.K.

Deleted: 4

\section{Materials, Theoretical Results and Discussion}

\subsection{Experimental details and materials.}

$\underline{\text { Composite } \mathrm{R} 6 \mathrm{G} / \mathrm{TiO}_{2}}$ and $\mathrm{R} 800 / \mathrm{TiO}_{2}$ thin films were prepared by using porous $\mathrm{TiO}_{2}$ thin

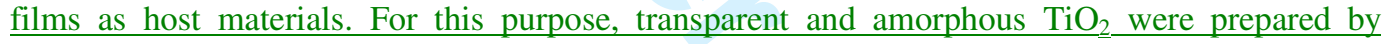
Glacing Angle Physical Vapor Deposition (GAPVD) at room temperature on quartz and silicon $\underline{\text { substrates. Evaporation was carried out in an electron bombardment evaporator by using } \mathrm{TiO}_{2}}$ pellets as target material. Stoichiometric thin films of $\mathrm{TiO}_{2}$ were obtained by performing the evaporation in $10^{-4}$ torrs of $\mathrm{O}_{2}$. The evaporation was carried out by placing the substrates at a glancing angle of $70^{\circ}$ with respect to the evaporator source. This geometry produces films with a $\underline{\text { tilted columnar microstructure and a high porosity }}{ }^{19-21}$. Thin films with a thickness around $400 \mathrm{~nm}$ were prepared by this method. In the present case the porosity of the films was estimated to be $35 \%$ of the total volume of the films, with a $70 \%$ of pores consisting of mesopores. A full account of the characteristics of these films can be found in a previous publication ${ }^{14}$. 
$\underline{\text { UV-visible absorption spectra in transmission mode were recorded with a Perkin-Elmer }}$ Lambda 12 spectrometer for the thin films deposited on quartz plates. Although the absorbance is the typical magnitude used for presenting UV-vis absorption spectra of dyes in liquid solutions, we present here some spectra as the percentage of transmitted light. We have made this choice because this is the usual way of presenting these data when using optical thin films ${ }^{22}$.

A chloride salt of R6G and R800 dye molecules was used for the experiments. The salts were supplied by ALDRICH and used without further purification. In solution, the cationic R6G or R800 bear a positive charge, a feature that is essential for the incorporation of the dye into the $\underline{\mathrm{TiO}_{2}} \underline{\text { thin films. }}$

A $10^{-4} \mathrm{M}$ solutions of the dyes in water at controlled values of $\mathrm{pH}$ were used for the infiltration experiments. The $\mathrm{pH}$ of the solution was controlled between 1.9 and 6.6 by adding given amounts of $\mathrm{HCl}$ or $\mathrm{NaOH}$. The $\mathrm{TiO}_{2}$ films were immersed in one of these solutions and maintained there for $10 \mathrm{~min}$. The samples were then removed from the solution and washed with water at the same $\mathrm{pH}$ than that of the dye solutions. In general, the intensity of the colour of the films changed with the $\mathrm{pH}$ of the solution, a feature that suggests the dependence between this parameter and the ability to incorporate the dye molecules into the films.

shows a series of UV-vis transmission spectra recorded for $\mathrm{TiO}_{2}$ thin films containing different concentrations of $\mathrm{R} 6 \mathrm{G}$ and $\mathrm{R} 800$, as indicated in Table 1 . The spectra are characterized by the presence of a series of bands typical of the R6G dye molecules (i.e., bands centred at $\sim 520$ $\underline{\mathrm{nm} \text { ) and R800 (i.e., bands centred at } \sim 650 \mathrm{~nm})^{14} \text { superimposed on the typical oscillations due to }}$ 
interference phenomena between a substrate and a transparent layer of different refraction index ${ }^{14}$.

For the purposes of the present work, the most important result is the dependence of the intensity of the features attributed to the two dye molecules and the $\mathrm{pH}$ of the solution used for the preparation of the films. Thus, it is observed that the intensity of the R6G features are strongly dependent on the $\mathrm{pH}$, increasing with this parameter. By contrast, R800 is little or no sensitive to this parameter and the intensity of its spectral features remains almost invariable for all the pHs. This different behaviour suggests that these two molecular cations interact differently with the $\underline{\text { surface of } \mathrm{TiO}_{2}}$ and that, particularly for the $\mathrm{R} 800$, the state of charge on the $\mathrm{TiO}_{2}$ does not affect significantly the adsorption of this molecule.

\subsection{Theoretical results and discussion.}

Once a suitable set of interatomic potentials is obtained, we created the unit cells that model the systems of interest. The simplest cell to study the adsorption of rhodamines is a bare surface formed by a slab of $\mathrm{TiO}_{2}$ in vacuum. We generated a $17 \AA$ slab exposing the (101) surface of anatase $\mathrm{TiO}_{2}$, with a $\left(6 \mathrm{a}_{\mathrm{x}} \times 8 \mathrm{a}_{\mathrm{y}}\right)$ periodic replication of the elementary experimental cell of dimensions $\mathrm{a}_{\mathrm{x}}=5.44 \AA$ and $\mathrm{a}_{\mathrm{y}}=3.776 \AA$. The simulation cell contains $10 \mathrm{Ti}$ atoms and $20 \mathrm{O}$ atoms, giving a total of $480 \mathrm{Ti}$ atoms and $960 \mathrm{O}$ atoms. The dimensions of the unit cell are $32.66 \AA$ x 30.2 $\AA \mathrm{x} 50 \AA$, and the angle between $\mathrm{a}_{\mathrm{x}}$ and $\mathrm{a}_{\mathrm{y}}$ is $110.30^{\circ}$. There is a vacuum gap of $33 \AA$ between the slabs. The charges on the $\mathrm{Ti}$ and $\mathrm{O}$ atoms are $2.196 \mathrm{e}$ and $-1.098 \mathrm{e}$ respectively. Since we are interested in studying the effect of $\mathrm{pH}$ on the adsorption energy $\left(\mathrm{E}_{\mathrm{ad}}\right)$ of rhodamines, we also generated three unit cells to model different values of $\mathrm{pH}$ : 1) hydroxylated surface under neutral conditions, 2) hydroxylated surface under acidic conditions and 3) hydroxylated surface under basic conditions. Surface 1 is created by adding an $\mathrm{H}$ atom to each bridging $\mathrm{O}$ atom and a hydroxyl 
1

2

3

4

5

6

7

8

9

10 to each Ti atom, as shown in Figure 1. The charge of the $\mathrm{O}$ atoms in the hydroxyl groups is $0.848 \mathrm{e}$ and the charge of the $\mathrm{H}$ atoms is $0.424 \mathrm{e}$. To model surface 2, we take into account that at low $\mathrm{pHs}$ there will be a large number of $\mathrm{H}$ atoms available to interact with the surface. The following or a similar process will happen readily:

1) $\mathrm{Surf}-\mathrm{TiOH}+\mathrm{H}^{+} \rightarrow$ Surf- $-\mathrm{Ti}^{+}+\mathrm{H}_{2} \mathrm{O}$,

i.e. a proton from the acidic solution will interact with a hydroxyl group at the surface and form a water molecule, which will then move into the solution. Once the surface is dried, this water molecule is removed from the surface and our model of a $\mathrm{TiO}_{2}$ surface in acidic conditions will have a positive charge of $+1 \mathrm{e}$ left in the surface. Since the charge of the hydroxyl group removed from the surface is only $-0.424 \mathrm{e}$, there will be an additional $+0.576 \mathrm{e}$ to be distributed among the atoms of the surface. This charge was distributed among the surface atoms as shown is Table 3. Surface 3 is created taking into account a different process occurring in the basic solution. Since under these conditions there is a large amount of $\mathrm{OH}^{-}$groups, the following process will take place:

2) Surf- $\mathrm{Ti}-\mathrm{OH}+\mathrm{OH}^{-} \rightarrow$ Surf- $-\mathrm{O}^{-}+\mathrm{H}_{2} \mathrm{O}$.

Thus, the result of the interaction between the hydroxylated surface and the $\mathrm{OH}^{-}$species from the solution is the removal of one proton from the surface to form a water molecule. This water molecule will be removed into the basic solution, leaving a bridging $\mathrm{O}$ at the surface and a charge of -1e, distributed among the atoms as shown in_Table 3. Processes 1) and 2) are similar to the common mechanisms considered within the PZC theory of oxides ${ }^{15}$.

\subsubsection{Adsorption of rhodamine 6G.}

Deleted: 4

Deleted: 1 
The UV-vis spectra shown in a suggest that the maximum adsorption of rhodamine $6 \mathrm{G}$ molecules will occur under basic conditions. This experimental behaviour is not unexpected, since these dye molecules are positively charged, and there will be an electrostatic attraction between this charge and the negative charge present on the surface due to the basic solution. As the $\mathrm{pH}$ decreases, the amount of negative charges on the surface decreases, and therefore the adsorption decreases. When the $\mathrm{pH}$ is below the PZC, the surface is positively charged, a situation that must produce an electrostatic repulsion between the positive charge of the rhodamine molecule and the positive charges on the surface induced by the proton adsorbed from the acidic solutions. This general trend is also observed in the simulations. Figure 5 shows a snapshot of the simulation of the adsorption of rhodamine $6 \mathrm{G}$ on a fully hydroxylated surface, modelling the surface for neutral conditions. As shown in Table 4 (where the values of the energies of adsorption of the two rhodamine molecules on the four types of surfaces are shown), under basic conditions the adsorption energy of rhodamine $6 \mathrm{G}$ is $-46.5 \mathrm{kcal} / \mathrm{mol}$. Under neutral conditions $\mathrm{E}_{\mathrm{ad}}$ decreases to $28.6 \mathrm{kcal} / \mathrm{mol}$, and under acidic conditions it decreases further to $-7.1 \mathrm{kcal} / \mathrm{mol}$. The latter value is negative, suggesting that there might be some adsorption of rhodamine $6 \mathrm{G}$ under acidic conditions, in disagreement with what is experimentally observed. This apparent contradiction might be due to the simplicity of the model. $E_{a d}$ is calculated as the difference in energy between two states. One state consists of two systems, the isolated $\mathrm{TiO}_{2}$ surface and the isolated rhodamine molecule. The other state consists of the rhodamine molecule adsorbed onto the surface. A more accurate value of $\mathrm{E}_{\mathrm{ad}}$ would be obtained if the interaction of the rhodamine molecule with water molecules would have been taken into account accurately. The interaction rhodamine-water would cause a decrease of the adsorption energies of the two rhodamine molecules under all $\mathrm{pH}$ conditions. For this reason, this initial study only provides qualitative information about the 
general trends of adsorption energy, predicting relative energetic differences, not the actual absolute values of adsorption energy.

The dynamics of the rhodamine $6 \mathrm{G}$ molecule adsorbed onto the different surfaces shows significant variations.

In Figure 6 the values of the $(x, y)$ coordinates of some relevant atoms of the molecule are plotted. The shape of the cell (from a top view) is also shown. In Figure 6a we can see the (x,y) values of the atom $\mathrm{H} 7$ of the rhodamine $6 \mathrm{G}$ when adsorbed on the bare, non-hydroxylated surface. The adsorption energy, in that case $-51.0 \mathrm{kcal} / \mathrm{mol}$, is higher than that of the other three cases in which the surface is hydroxylated. But there are no experimental results to be compared with these data, since bare $\mathrm{TiO}_{2}$ surfaces are quickly hydrated and hydroxylated. The set of points are scattered over a wide range of values, indicating that the attraction between the molecule and the surface is evenly distributed over the surface, i.e. it is very easy for the molecule to hop around the surface. Under basic conditions we observe the opposite effect: there is a strong attraction towards the negatively charged surface defect, a feature which creates a preference for the molecule to stay around it. In Figure $6 \mathrm{~b}$ we see the $(\mathrm{x}, \mathrm{y})$ values of the atoms $\mathrm{O} 1$ and $\mathrm{H} 7$, as well as the position of the $\mathrm{O}$ atom that has lost its $\mathrm{H}$ due to the basic solution. The positions of the $\mathrm{O} 1$ and $\mathrm{H} 7$ atoms are localised in small areas, indicating that the molecule does not diffuse easily once it is absorbed. Under neutral conditions (Figure 6c) the mobility of the molecule is higher, and $\mathrm{E}_{\mathrm{ad}}$ is lower, -28.6 $\mathrm{kcal} / \mathrm{mol}$, a result that agrees with the experimental observations. Under acidic conditions the mobility is still higher, as suggested by the scattered set of points corresponding to the movement of the $\mathrm{H} 7$ atom (Figure 6d). The molecule moves around the Ti atom which has lost its hydroxyl group, and is part of the positively charged defect. During the simulation, the phenyl moiety of the rhodamine $6 \mathrm{G}$ molecule is often inserted within the region previously occupied by the hydroxyl group. $\mathrm{E}_{\mathrm{ad}}$ is now $-7.1 \mathrm{kcal} / \mathrm{mol}$, a value which is much smaller than in the case of adsorption 
under neutral conditions. The most relevant geometric parameters that describe the adsorption of the rhodamine $6 \mathrm{G}$ molecules are the angles $\alpha$ and $\beta . \alpha$ is defined as the angle between the axis $\mathbf{a}$ of the molecules (which is shown in Figure 2), and the $\mathbf{z}$ axis of the unit cell. Analogously, $\beta$ is the angle between the molecular axis $\mathbf{b}$ and the $\mathbf{z}$ axis. A value of $90^{\circ}$ in both angles would correspond to an adsorption geometry in which the molecule lies parallel to the surface. The convention we have used to calculate the angles means that an angle lower than $90^{\circ}$ implies that the corresponding molecular axis (a or b) points upwards, and viceversa. Figure 7 shows the values of the angles $\alpha$ and $\beta$ during the simulations, for the two rhodamine molecules at the four conditions of $\mathrm{pH}$ studied.

The average values for the whole simulations are shown in Figure 8. For rhodamine $6 \mathrm{G}$ the average value of the angle $\alpha$ is very close to $90^{\circ}$ in all cases. The larger deviation is found for the adsorption under basic conditions. The value of $88^{\circ}$ obtained suggests an adsorption almost parallel to the surface. The angle $\beta$ is more affected by the presence of the phenyl group, which has the effect of decreasing the adsorption angle of the molecule. As a result, the average value of the angle $\beta$ ranges from $80.7^{\circ}$, in the case of non-hydroxylated surface, to $84.0^{\circ}$ for the adsorption under acidic conditions. This higher angle for acidic conditions is due to the mentioned ability of the molecule to introduce the phenyl moiety within the region previously occupied by the removed hydroxyl group, a feature which permits a more parallel adsorption.

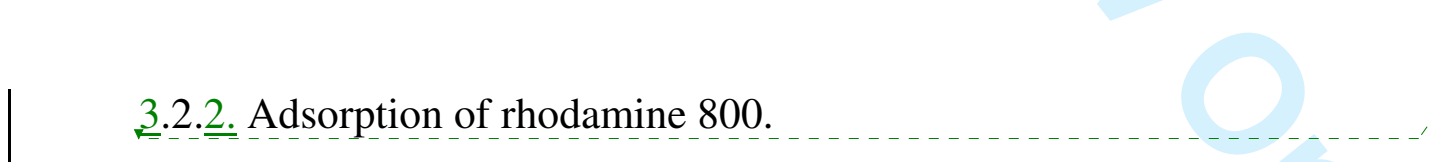

Deleted: 4 3.2.2. Adsorption of rhodamine 800.

The experimental observations suggest that the adsorption of rhodamine 800 is less affected than the rhodamine $6 \mathrm{G}$ by changes in the $\mathrm{pH}$ of the surface, although the maximum adsorption also takes place under basic conditions and the minimum under acidic conditions. The 
values of the energies of adsorption calculated from the simulations for basic, neutral and acidic conditions are $-51.6 \mathrm{kcal} / \mathrm{mol},-33.2 \mathrm{kcal} / \mathrm{mol}$ and $-29.4 \mathrm{kcal} / \mathrm{mol}$ respectively. The difference between the energies for neutral and acidic conditions is just $3.8 \mathrm{kcal} / \mathrm{mol}$, almost five times smaller than the difference between the values for neutral and basic conditions, which is 18.4 $\mathrm{kcal} / \mathrm{mol}$. This effect is in agreement with the observation that a low $\mathrm{pH}$ only produces a small decrease in the intensity of the UV-vis adsorption bands (see b).The simulations provide some hints to understand the reasons for this behaviour. As it happens for rhodamine $6 \mathrm{G}$, under basic conditions $\mathrm{E}_{\mathrm{ad}}$ is higher because the negative charge of the surface site defect modelling the basic conditions attracts the positive charge of the molecule. The $\mathrm{N}$ atom of the nitrile group of the rhodamine R800 molecule (N3 in Figure 2b) has a negative charge of -0.417 e. Therefore, the negatively charged site at the surface interacts preferentially with the opposite side of the molecule, where most of the positive charge of the molecule is concentrated. It can be observed in Figure $6 \mathrm{f}$ that the $\mathrm{N}$ atom does not get close to the surface $\mathrm{O}$ atom. To represent the movement of the xanthene moiety we have chosen the atom O1. It has a small negative charge $(-0.183 \mathrm{e})$, and is surrounded by positive charges, so the position of the $\mathrm{O} 1$ atom is oscillating around the surface $\mathrm{O}$ atom. Regarding Looking to the angles accounting for this interaction, the average values of both angles $\alpha$ and $\beta$ are within the range $90^{\circ}-92^{\circ}$ (see Figure 8 ), which means that the molecule is basically lying parallel to the surface.

In the surface that models neutral conditions the negatively charged site defect is not present, and the interaction between the rhodamine molecule and the surface is mainly due to their mutual van der Waals interactions. As a result, $E_{a d}$ decreases from $-51.6 \mathrm{kcal} / \mathrm{mol}$ to -33.2 $\mathrm{kcal} / \mathrm{mol}$. The negatively charged $\mathrm{N}$ atom in the nitrile group is now mainly attracted to the positively charged $\mathrm{H}$ atoms of the hydroxyl groups, and falls in the potential well created by the $\mathrm{H}$ atoms belonging to three adjacent hydroxyl groups. This can be seen in Figure 6g, where we have 
plotted the coordinates of the atoms N3 and O1 of the rhodamine 800 molecules, as well as the coordinates of the $\mathrm{O}$ atoms of the hydroxyl groups, which are less mobile than the $\mathrm{H}$ atoms with which they are bonded. The distance from the superficial $\mathrm{H}$ atoms to the centre of the xanthene moiety, $2.82 \AA$, is roughly the same as in the case of adsorption under basic conditions, and the adsorption geometry in both cases is very similar. This similarity is also found for the values of the angles $\alpha$ and $\beta$, which lie within a range of $90^{\circ}-92^{\circ}$ (Figure $7 \mathrm{~g}$ and Figure 8 ), thus indicating that the adsorption is parallel to the surface.

Experimentally, the relatively high adsorption of rhodamine 800 under acidic conditions (which is very similar to the level of adsorption in neutral conditions) is somewhat unexpected, because under these conditions, both the surface and the rhodamine 800 molecule are positively charged. Our simulations provide a basis to understand why a significant adsorption takes place. The value of $E_{a d}$ predicted by our simulations is $-29.4 \mathrm{kcal} / \mathrm{mol}$, which is very close to the value obtained under neutral conditions, $-33.2 \mathrm{kcal} / \mathrm{mol}$. The reason why the electrostatic repulsion between the two charged systems does not produce a significant decrease in the value of $E_{a d}$ is due to the fact that the positive charge around the Ti atom at the surface does not interact directly with the positive charge of the rhodamine molecule. Instead, it is the negatively charged $\mathrm{N}$ atom of the nitrile group the one that is closer to it. Figure $6 \mathrm{~h}$ shows that the positively charged region of the molecule (which surrounds the $\mathrm{O} 1$ atom) stays as far away as possible from the Ti atom, whereas the N3 atom is attracted by the positive charge of the Ti atom. There is a change in the angles of adsorption respect to the cases of basic and neutral conditions. The average value of the angle $\alpha$, $90^{\circ}$, is similar to the previous cases, but the average value of the angle $\beta$ has increased to $95^{\circ}$ (Figure $7 \mathrm{~h}$ and Figure 8 ). This is due to the mentioned attraction between the N3 atom and the surface Ti atom, which tends to keep them together. Indeed, this attraction induces a decrease of the distance between the molecule and surface (which changes from $2.8 \AA$ to $2.7 \AA$ ). Since the rest 
1

2

3

4

5

6

7

8

9

10

11

12

13

14

15

16

17

18

19

20

21

22

23

24

25

26

of the molecule cannot get closer to the hydroxyl groups of the surface, this effect results in an increase of the adsorption angle $\beta$, i.e. the position of the $\mathrm{N} 3$ atom is lower than that of the rest of the molecule. This particular geometrical arrangement has the net effect of creating an attraction between two positively charged systems.

\section{Concluding remarks}

The simulations reported here offer a preliminary atomistic insight into the adsorption processes on $\mathrm{TiO}_{2}$ of two industrially relevant dye molecules, namely rhodamine $6 \mathrm{G}$ and rhodamine 800 . The task of simulating $\mathrm{TiO}_{2}$ surfaces is very challenging. Theoretical studies of the adsorption of molecules are often carried out by employing bare $\mathrm{TiO}_{2}$ surfaces. Our results show that there are large differences in adsorption energies and geometries when the state of the surface is changed. Thus, for the two studied molecules the adsorption energy on a hydroxylated surface is almost half of that calculated in the case of a bare surface. One of the greatest challenges regarding the simulation of $\mathrm{TiO}_{2}$ surfaces is to model the effect of the different $\mathrm{pHs}$. Using two models to simulate high and low $\mathrm{pH}$ conditions, we have calculated the adsorption energies of the two molecules under basic, neutral and acidic conditions. For rhodamine 6G the simulations predict a high energy of adsorption and therefore much adsorption under basic conditions, less adsorption under neutral conditions, and practically no adsorption under acidic conditions. For rhodamine 800 there is a high energy of adsorption under basic conditions, while the adsorption energies under neutral and acidic conditions are lower than the latter, but very similar to each other. These results are in qualitative agreement with the experimental observations, which 
provides additional confidence on the ability of the simulations to model realistic adsorption conditions. However, despite this success in achieving a qualitative agreement between experimental and theoretical results, there are still many factors involved in the adsorption of molecules on $\mathrm{TiO}_{2}$ which we have not taken into account. For example, we have studied the final states, in which the rhodamine molecules are adsorbed onto the dry surface, but we have not modelled the transition from the wet to the dry $\mathrm{TiO}_{2}$ surface. This is an interesting process, since there is a loss of water molecules, while the rhodamine molecules are kept attached to the surface. Another relevant factor that influences the adsorption of rhodamine molecules is the presence of counterions $^{43,45}$. On the other hand, there is a rich variety of ways in which rhodamine molecules can interact, both in solution and on the surface, such as forming monomers, H-dimers, J-dimers, etc $^{6-11}$, which have a great influence on the photoluminescence properties ${ }^{21,46,47}$. Thus another interesting problem is to asses how the dimerisation process affects the adsorption on the surfaces. The ultimate goal of the inclusion of all these other effects would be to obtain a more accurate description of these systems, which could provide theoretical data to guide the experimental research. For these reasons an intense theoretical work is being carried out in our group along this line.

\section{Acknowledgements}

We dedicate this work to the memory of José Antonio Mejías, an excellent friend and good scientist, who put the first stones of this research line in our group. We will always remember him kindly. We thank the Ministry of Science and Education of Spain (project MAT 200765764/NAN2004-09317 and the CONSOLIDER INGENIO 2010-CSD2008-00023) and the Junta de Andalucía (projects TEP2275 and P07-FQM-03298) for financial support. 


\section{Page 19 of 42}

1

2

3

4

5

6

7

8

10

11

12

13

14

15

16

17

18

19

20

21

22

23

24

25

26

27

28

29

30

34

35

36

37

38

39

40

41

42

43

44

45

46

47

48

49

50

51

52

53

54

55

56

57

58

59

60

http://mc.manuscriptcentral.com/tandf/jenmol 


\section{Table 1}

Concentration of the adsorbed dyes in the porous $\mathrm{TiO}_{2}$ thin films as a function of the $\mathrm{pH}$. 


\section{Page 21 of 42}

1

2

3

4

5

6

7

8

9

10

11

12

13

14

15

16

17

18

19

20

21

22

23

24

25

26

27

28

29

30

31

32

33

34

35

36

37

38

39

40

41

42

43

44

45

46

47

48

49

50

51

52

53

54

55

56

57

58

59

60

\begin{tabular}{|c|c|c|c|c|c|c|c|}
\hline & $\begin{array}{c}\text { Torsional } \\
\text { angle } \\
10-1-4-5\end{array}$ & $\begin{array}{l}\text { Dist. } \\
1-2\end{array}$ & $\begin{array}{l}\text { Dist } \\
2-3\end{array}$ & $\begin{array}{c}\text { Dist. } \\
4-5\end{array}$ & $\begin{array}{l}\text { Dist. } \\
5-11\end{array}$ & $\begin{array}{l}\text { Angle } \\
1-4-5\end{array}$ & $\begin{array}{l}\text { Angle } \\
1-2-3\end{array}$ \\
\hline $\begin{array}{l}\text { Predota et al. } \\
\text { Plus added terms. }\end{array}$ & $126.2^{\circ}$ & $1.93 \AA$ & $1.01 \AA$ & $0.97 \AA$ & $2.73 \AA$ & $127.8^{\circ}$ & $119.8^{\circ}$ \\
\hline DFT & $122.3^{\circ}$ & $1.87 \AA$ & $0.98 \AA$ & $0.98 \AA$ & $2.49 \AA$ & $126.2^{\circ}$ & $118.3^{\circ}$ \\
\hline
\end{tabular}

\section{Table 2}

Values of some of the important geometrical features of the (101) hydroxylated anatase surface, obtained with DFT and with the interatomic potentials developed by Predota et al. ${ }^{23,28}$, including the new terms that improve the description of the $\mathrm{O}-\mathrm{H}$ bonds for this particular surface. 


\begin{tabular}{|c|c|c|c|}
\hline Atom & $\begin{array}{l}\text { Charge in } \\
\text { basic conditions }\end{array}$ & $\begin{array}{l}\text { Charge in } \\
\text { neutral conditions }\end{array}$ & $\begin{array}{l}\text { Charge in } \\
\text { acidic conditions }\end{array}$ \\
\hline 1-Ti & 2.124 & 2,196 & 2.268 \\
\hline 2-O & \begin{tabular}{|c|}
-0.920 \\
\end{tabular} & $-0,848$ & No atom \\
\hline 3-H & 0.352 & 0,424 & No atom \\
\hline 4-O & -1.170 & $-1,098$ & -1.026 \\
\hline 5-H & No atom & 0,424 & 0.496 \\
\hline 6-O & -1.170 & $-1,098$ & -1.026 \\
\hline 7-O & \begin{tabular}{|l|}
-1.170 \\
\end{tabular} & $-1,098$ & -1.026 \\
\hline 8-O & -1.170 & $-1,098$ & -1.026 \\
\hline 9-Ti & 2.124 & 2,196 & 2.268 \\
\hline $10-0$ & $-1,098$ & $-1,098$ & -1.026 \\
\hline
\end{tabular}

\section{Table 3}

Charges of all the atoms involved in the defects appearing at high and low $\mathrm{pH}$, as well as the charges of the atoms of the hydroxylated surface under neutral conditions. 


\section{Table 4}

Energies of adsorption, $E_{a d}$, of the two rhodamine molecules studied on the (101) surface of anatase. All energies are in $\mathrm{kcal} / \mathrm{mol}$. 
a)
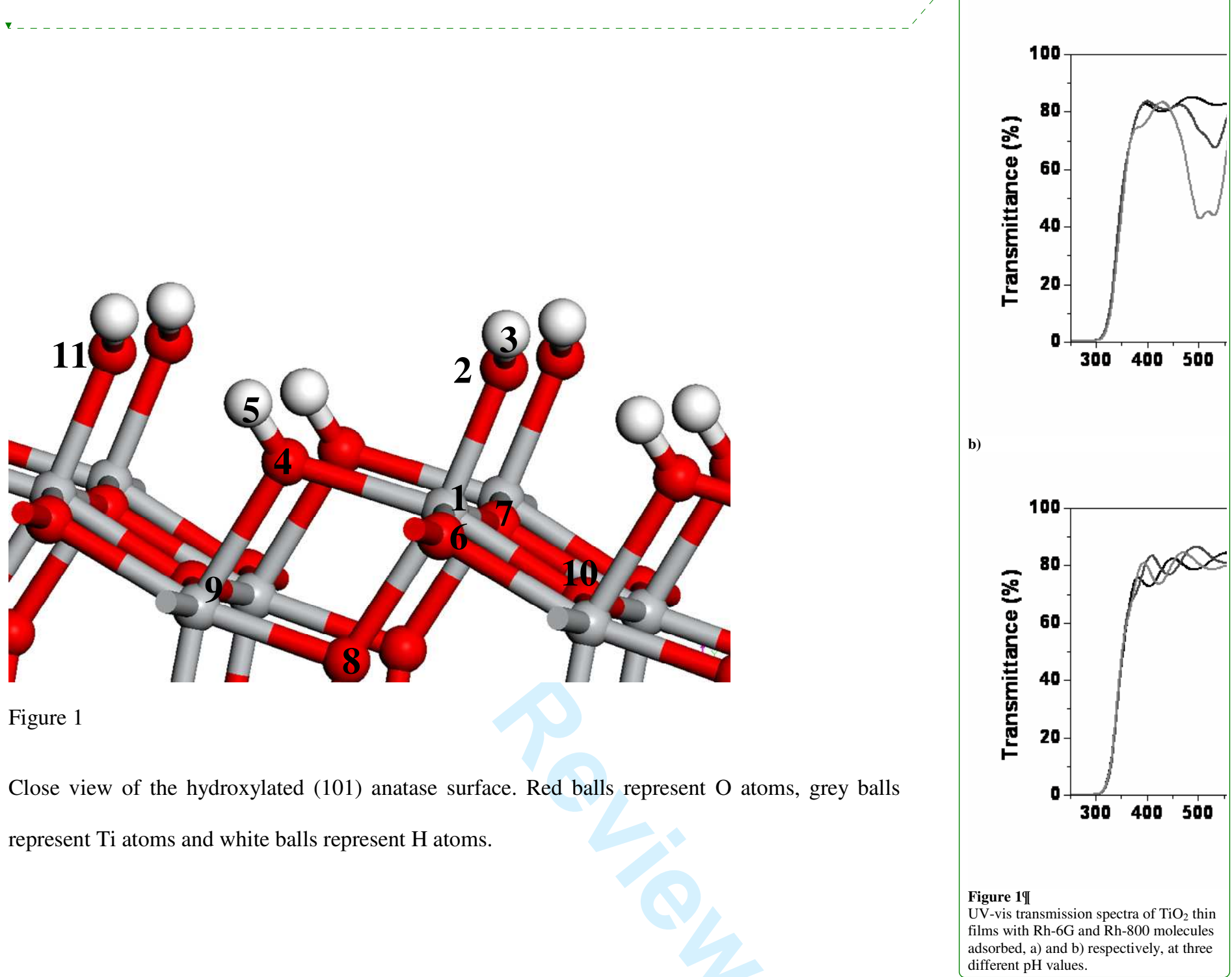

Figure 1

Close view of the hydroxylated (101) anatase surface. Red balls represent $\mathrm{O}$ atoms, grey balls represent $\mathrm{Ti}$ atoms and white balls represent $\mathrm{H}$ atoms. 


\section{Page 25 of 42}

1

2

3

4

5

6

7

8

9

10

11

12

13

14

15

16

17

18

19

20

21

22

23

24

25

26

27

28

29

30

31

32

33

34

35

36

37

38

39

40

41

42

43

44

45

46

47

48

49

50

51

52

53

54

55

56

57

58

59

60 a)

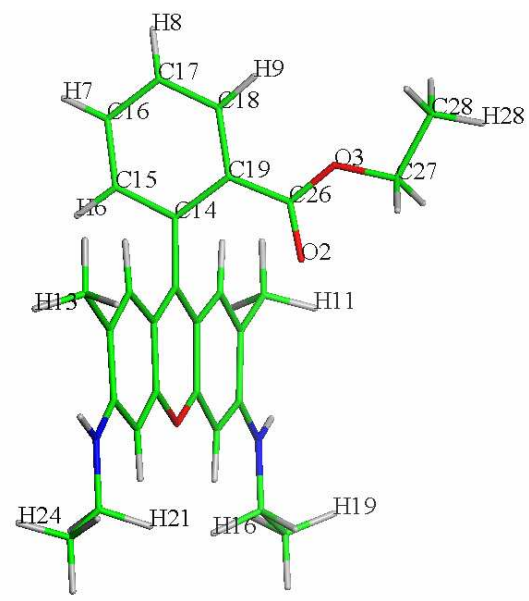

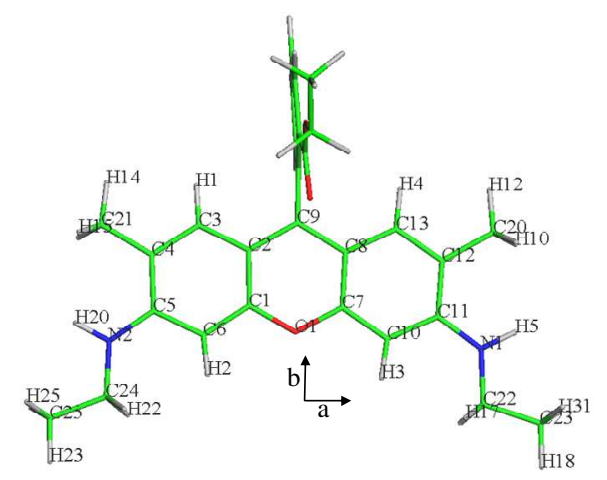

b)

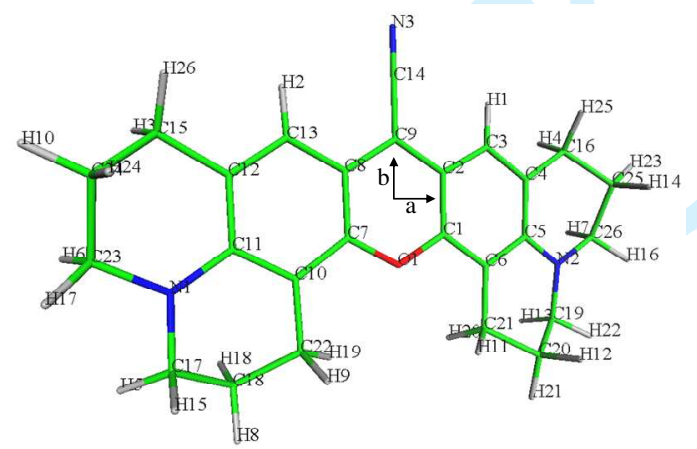

Figure 2

a) Two views of a rhodamine $6 \mathrm{G}$ molecule. b) A view of a rhodamine 800 molecule. The figures show the numbering assigned to each atom, which are used to assign the force field atom types and | charges in SI_Table $\mathbf{1}$ and SI_Table 2, The molecular axis $\mathbf{a}$ and $\mathbf{b}$ are also shown. In both figures green, blue, red and white sticks represent $\mathrm{C}, \mathrm{N}, \mathrm{O}$ and $\mathrm{H}$ atoms respectively.

Deleted: and

Formatted: Font: Bold

Formatted: Font: Bold 


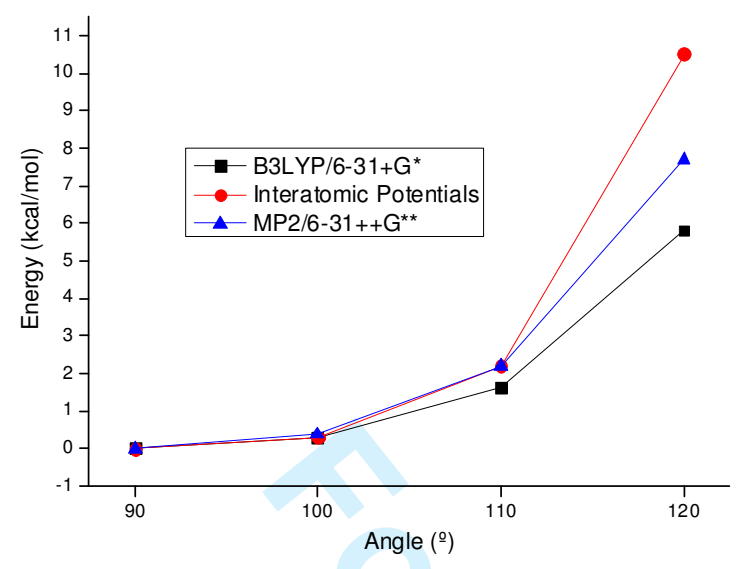

\section{Figure 3}

Change in energy as the angle between the xanthene and phenyl moieties is changed, calculated with two ab initio methods (B3LYP/6-31+G* and MP2/6-31++G**) and with the classical interatomic potentials used in this study. 


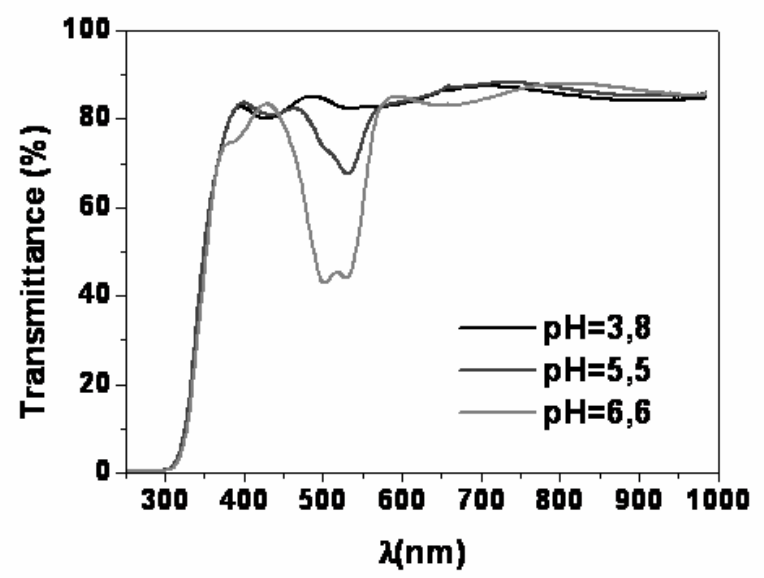

a)

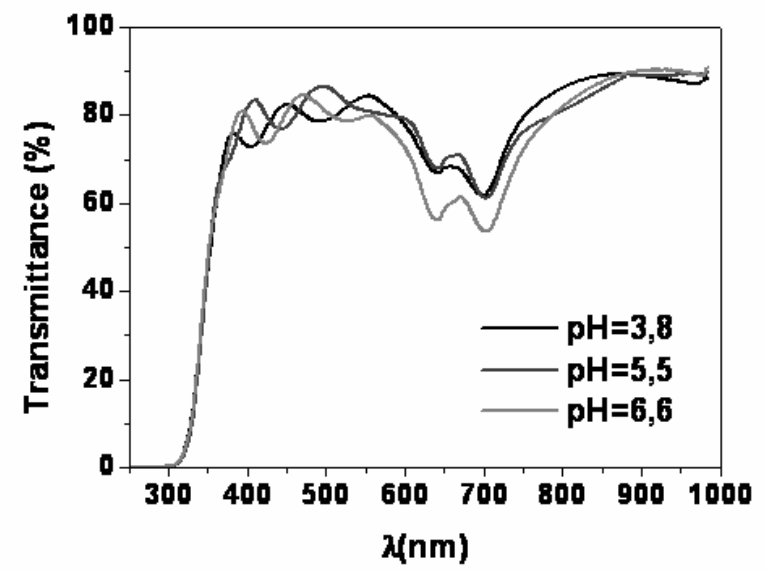

b)

\section{Figure 4}

UV-vis transmission spectra of $\mathrm{TiO}_{2}$ thin films with $\mathrm{Rh}-6 \mathrm{G}$ and $\mathrm{Rh}-800$ molecules adsorbed, a) and b) respectively, at three different $\mathrm{pH}$ values. 


1
2
3
4
5
6
7
8
9
10
11
12
13
14
15
16
17
18
19
20
21
22
23
24
25
26
27
28
29
30
31
32
33
34
35
36
37
38
39
40
41
42
43
44
45
46
47
48
49
50
51
52
53
54
55
56
57
58
59
60

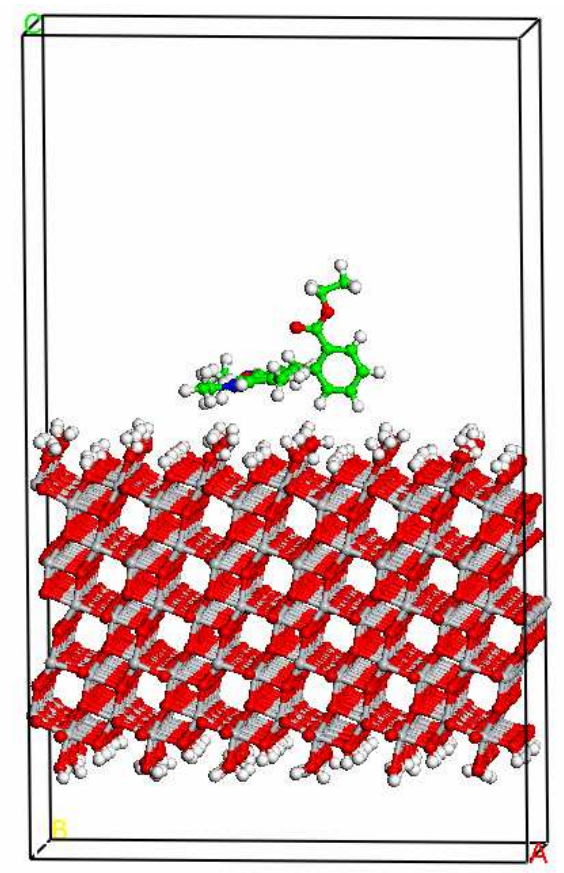

\section{Figure 5}

Ball and stick view of the simulation cell used to study the adsorption of rhodamine $6 \mathrm{G}$ in a fully hydroxylated surface, under neutral $\mathrm{pH}$ conditions. Green, blue, red, white and grey balls atoms represent $\mathrm{C}, \mathrm{N}, \mathrm{O}, \mathrm{H}$ and $\mathrm{Ti}$ atoms respectively. 
a)

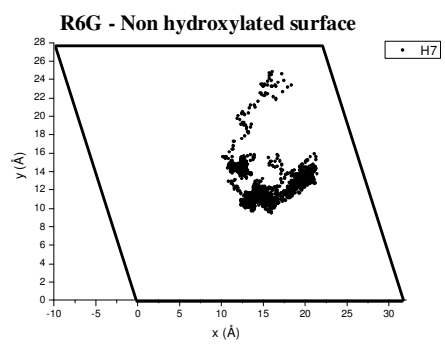

b)
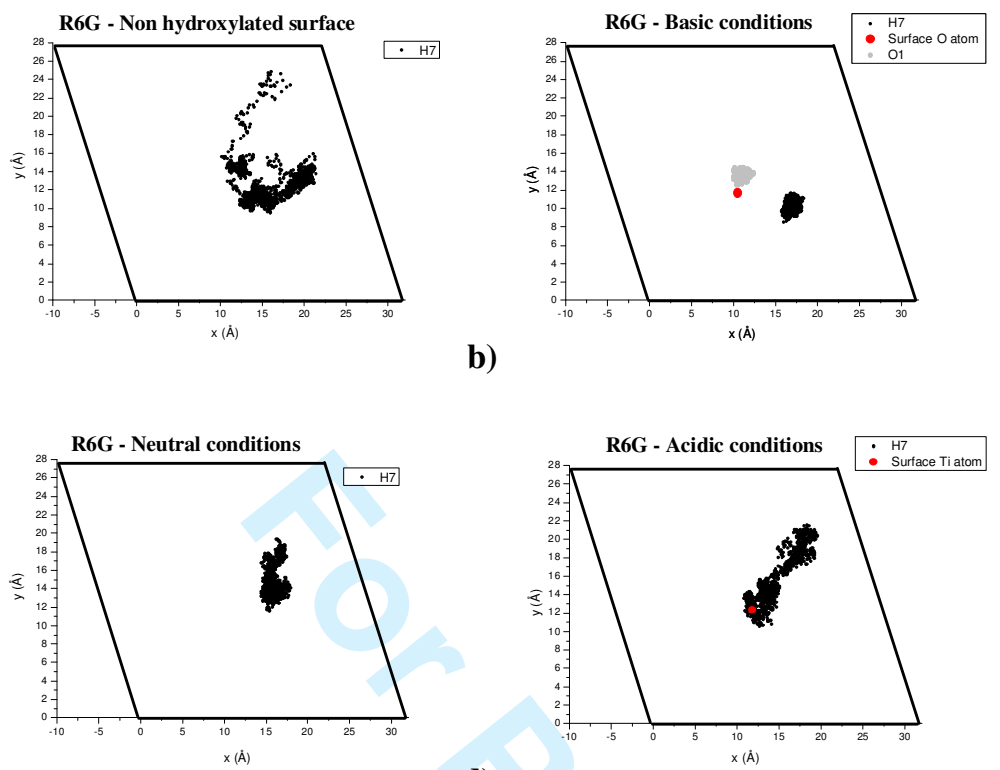

c)

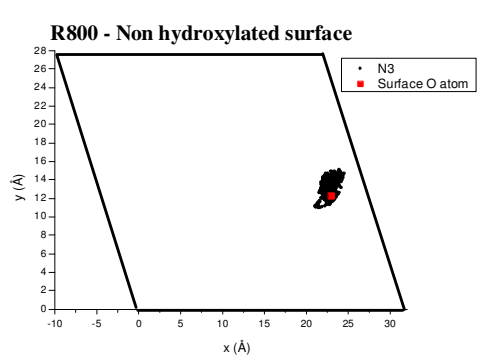

e)

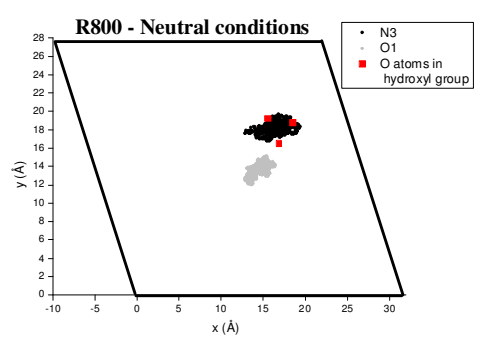

g)

f)

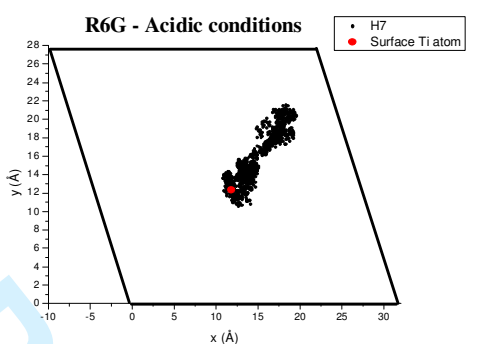

d)
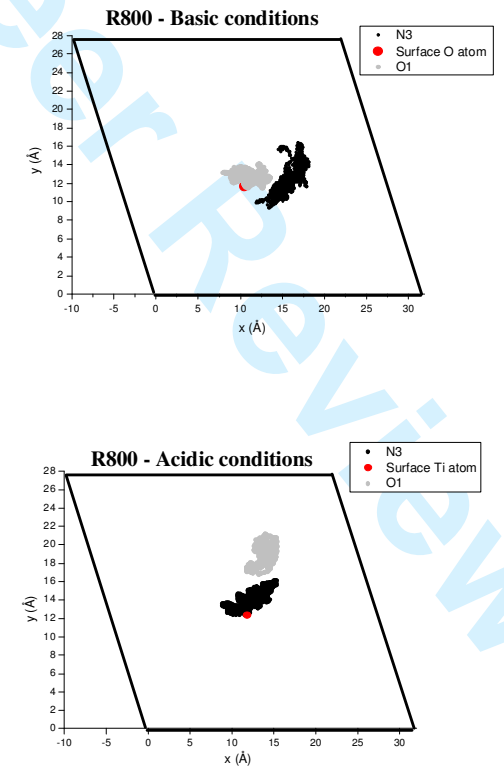

h)

\section{Figure 6}

Plot of the values of the $(\mathrm{x}, \mathrm{y})$ coordinates of some relevant atoms, taken every $0.1 \mathrm{ps}$ during the whole simulations. a) R6G on non-hydroxylated surface, b) R6G under basic conditions, c) R6G under neutral conditions, d) R6G under acidic conditions, e) R800 on non-hydroxylated surface, f) R800 under basic conditions, g) R800 under neutral conditions, h) R800 under acidic conditions. 
a)

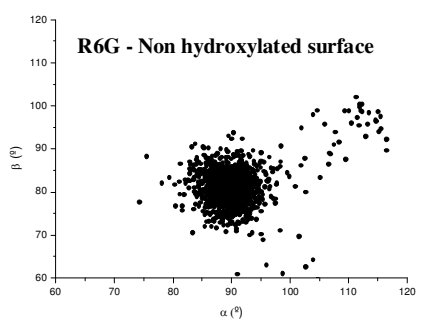

b)
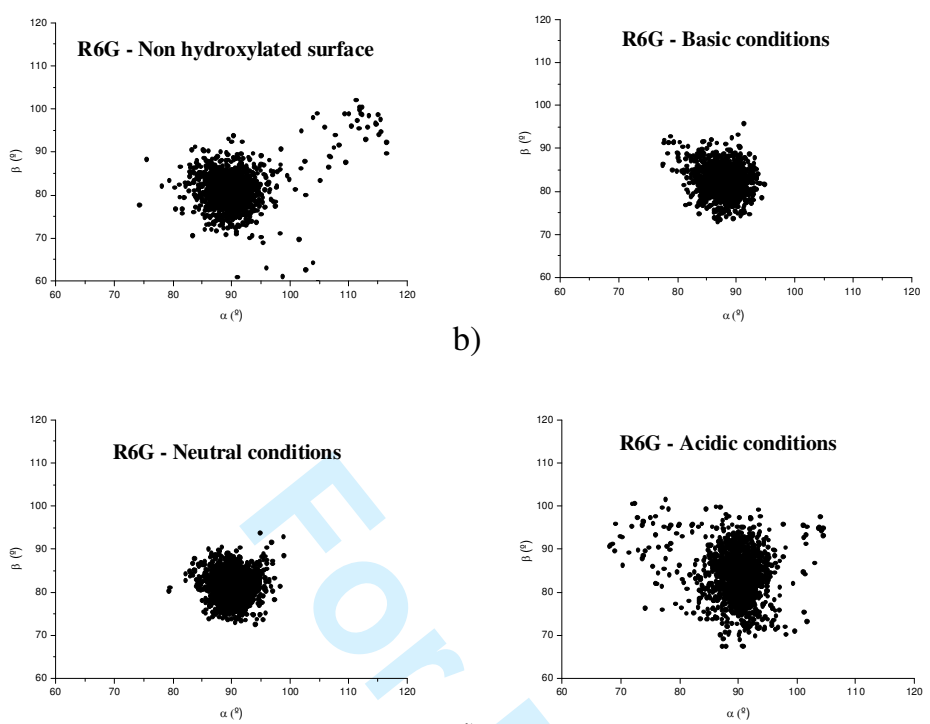

c)

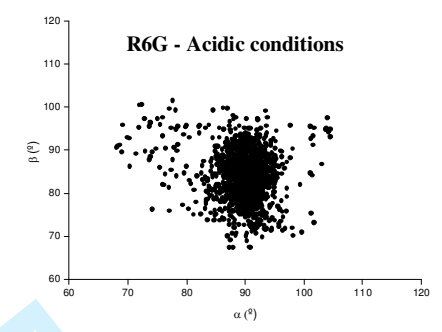

d)

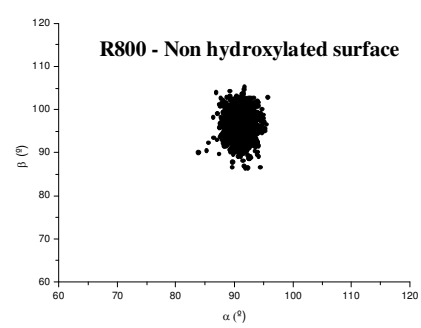

e)

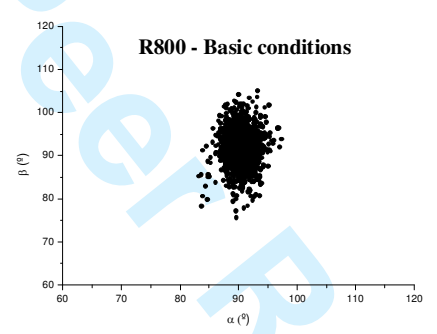

f)

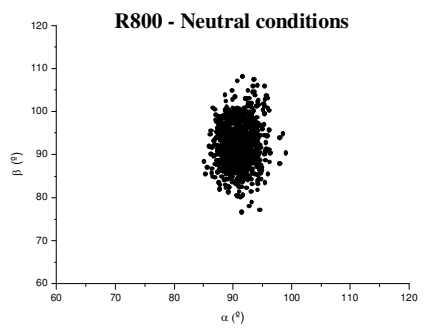

g)

h)

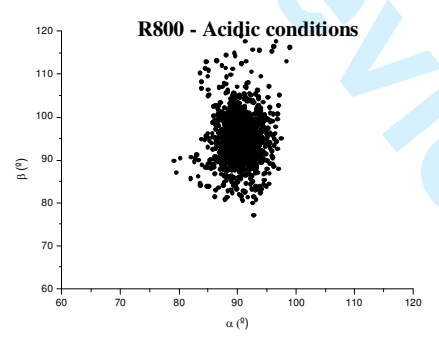

\section{Figure 7}

Values of the angles $\alpha$ and $\beta$ during the simulations for the different simulations. $\alpha$ ( $\beta$ ) is defined as the angle between the axis $\mathbf{a}(\mathbf{b})$ of the molecules (which is shown in Figure 2), and the $\mathbf{z}$ axis of the unit cell. a) R6G on non-hydroxylated surface, b) R6G under basic conditions, c) R6G under neutral conditions, d) R6G under acidic conditions, e) R800 on non-hydroxylated surface, f) R800 under basic conditions, g) R800 under neutral conditions, h) R800 under acidic conditions. 


\section{Page 31 of 42}

1

2

3

4

5

6

7

8

9

10

11

12

13

14

15

16

17

18

19

20

21

22

23

24

25

26

27

28

29

30

31

32

33

34

35

36

37

38

39

40

41

42

43

44

45

46

47

48

49

50

51

52

53

54

55

56

57

58

59

60

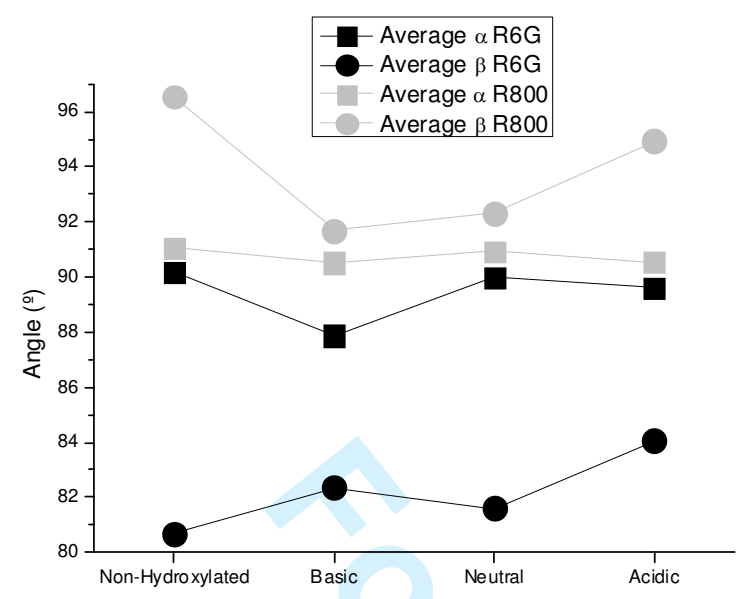

Figure 8

Average values of the angles $\alpha$ and $\beta$ during the simulations. 


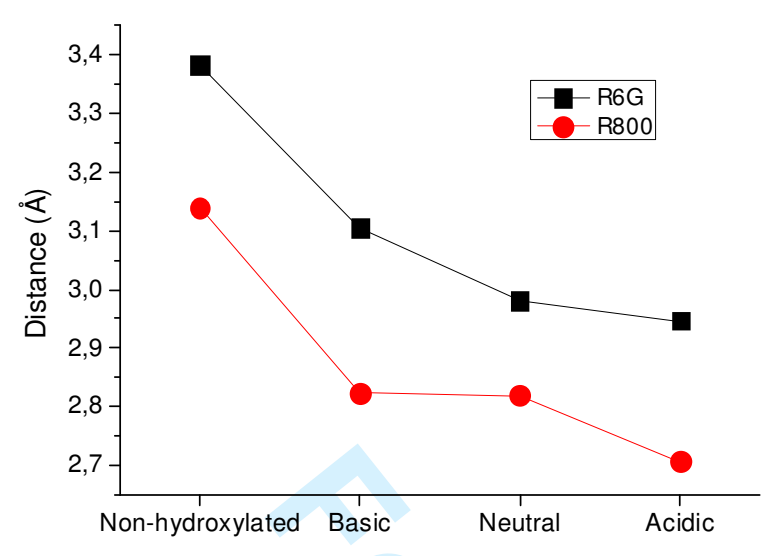

Figure 9

Average distance between the surfaces and the rhodamine molecules.

20

21

22

23

24

25

26

27

28

29

30

31

32

33

34

35

36

37

38

39

40

41

42

43

44

45

46

47

48

49

50

51

52

53

54

55

56

57

58

59

60

http://mc.manuscriptcentral.com/tandf/jenmol 


\section{Page 33 of 42}

Supplementary Information

\begin{tabular}{|c|c|c|c|c|c|}
\hline Atom name & $\frac{\text { Force Field }}{\text { type }}$ & Charge & Atom name & $\frac{\text { Force Field }}{\text { type }}$ & Charge \\
\hline C1 & C R & 0,48 & 03 & 02 & -0.46 \\
\hline C2 & $\mathrm{CR}$ & -0.139 & $\mathrm{C} 27$ & C 3 & 0.346 \\
\hline C3 & $\mathrm{C} R$ & $\underline{-0.287}$ & C28 & C 3 & -0.25 \\
\hline C4 & $\underline{\mathrm{C} R}$ & $\underline{0.114}$ & $\underline{\mathrm{H} 1}$ & $\underline{\mathrm{H}}$ & $\underline{0.173}$ \\
\hline C5 & C R & 0.287 & $\mathrm{H} 2$ & $\mathrm{H}$ & 0.231 \\
\hline$\underline{\mathrm{C} 6}$ & $\underline{C R}$ & $\underline{-0.438}$ & $\underline{\mathrm{H} 3}$ & $\underline{\mathrm{H}}$ & $\underline{0.238}$ \\
\hline 01 & $\mathrm{O} R$ & $\underline{-0.385}$ & $\mathrm{H} 4$ & $\mathrm{H}$ & 0.17 \\
\hline $\mathrm{C} 7$ & $\mathrm{CR}$ & 0.487 & $\underline{\mathrm{H} 5}$ & $\mathrm{H} \quad \mathrm{HB}$ & 0.365 \\
\hline C8 & $\underline{C R}$ & -0.136 & $\underline{\mathrm{H} 6}$ & $\underline{\mathrm{H}}$ & $\underline{0.139}$ \\
\hline$\underline{\text { c9 }}$ & $\underline{\mathrm{C} R}$ & $\underline{0.08}$ & $\underline{\mathrm{H} 7}$ & $\underline{\mathrm{H}}$ & $\underline{0.15}$ \\
\hline C10 & $\underline{C} R$ & -0.46 & $\underline{\mathrm{H} 8}$ & $\underline{\mathrm{H}}$ & $\underline{0.155}$ \\
\hline C11 & C R & 0.31 & $\underline{\mathrm{H} 9}$ & $\underline{\mathrm{H}}$ & $\underline{0.148}$ \\
\hline C12 & $\mathrm{C} R$ & 0.106 & $\mathrm{H} 10$ & $\mathrm{H}$ & 0.089 \\
\hline $\mathrm{C} 13$ & C R & -0.285 & $\mathrm{H} 11$ & $\mathrm{H}$ & 0.123 \\
\hline N1 & $\mathrm{NR}$ & $\underline{-0.534}$ & H12 & $\underline{\mathrm{H}}$ & $\underline{0.083}$ \\
\hline C14 & $\underline{C R}$ & $\underline{0.428}$ & $\mathrm{H} 13$ & $\underline{\mathrm{H}}$ & $\underline{0.125}$ \\
\hline C15 & $\underline{C} R$ & $\underline{-0.298}$ & H14 & $\underline{\mathrm{H}}$ & 0.093 \\
\hline C16 & C R & $\underline{-0.058}$ & H15 & $\underline{\mathrm{H}}$ & $\underline{0.089}$ \\
\hline C17 & C R & -0.161 & $\mathrm{H} 16$ & $\mathrm{H}$ & 0.045 \\
\hline$\underline{\mathrm{C} 18}$ & C R & -0.083 & $\underline{\mathrm{H} 17}$ & $\underline{\mathrm{H}}$ & 0.054 \\
\hline C19 & C R & -0.302 & H18 & $\underline{\mathrm{H}}$ & 0.079 \\
\hline C20 & C 3 & $\underline{-0.286}$ & $\underline{\mathrm{H} 19}$ & $\underline{\mathrm{H}}$ & $\underline{0.087}$ \\
\hline C21 & C 3 & $\underline{\underline{-0.303}}$ & $\underline{\mathrm{H} 2 \mathrm{O}}$ & $\underline{\mathrm{H} \quad \mathrm{HB}}$ & 0.357 \\
\hline C22 & C 3 & 0.166 & $\mathrm{H} 21$ & $\mathrm{H}$ & 0.063 \\
\hline$\underline{\mathrm{C} 23}$ & $\mathrm{C} 3$ & $\underline{-0.232}$ & $\underline{\mathrm{H} 22}$ & $\underline{\mathrm{H}}$ & $\underline{0.041}$ \\
\hline$\underline{\mathrm{N} 2}$ & $\underline{N R}$ & $\underline{-0.521}$ & $\underline{\mathrm{H} 23}$ & $\underline{\mathrm{H}}$ & $\underline{0.033}$ \\
\hline C24 & C 3 & $\underline{0.205}$ & $\mathrm{H} 24$ & $\underline{\mathrm{H}}$ & 0.079 \\
\hline$\underline{\mathrm{C} 25}$ & C 3 & $\underline{-0.242}$ & $\underline{\mathrm{H} 25}$ & $\underline{\mathrm{H}}$ & 0.061 \\
\hline $\mathrm{C} 26$ & C 2 & $\underline{0.784}$ & H26 & $\underline{\mathrm{H}}$ & $\underline{0.088}$ \\
\hline$\underline{\mathrm{O} 2}$ & 01 & -0.532 & $\mathrm{H} 27$ & $\mathrm{H}$ & -0.001 \\
\hline O3 & $\underline{02}$ & -0.46 & $\underline{\mathrm{H} 28}$ & $\underline{\mathrm{H}}$ & 0.002 \\
\hline C27 & C 3 & 0.346 & $\underline{\mathrm{H} 29}$ & $\underline{\mathrm{H}}$ & 0.071 \\
\hline C28 & C 3 & -0.25 & $\mathrm{H} 30$ & $\underline{\mathrm{H}}$ & 0.084 \\
\hline$\underline{\mathrm{H} 1}$ & $\mathrm{H}$ & $\underline{0.173}$ & H31 & $\underline{\mathrm{H}}$ & $\underline{0.085}$ \\
\hline
\end{tabular}

\section{SI_Table 1}

Atomic charges and DREIDING force field types of the atoms of rhodamine 6G shown in Figure 2a. 


\begin{tabular}{|c|c|c|c|c|c|}
\hline Atom name & $\frac{\text { Force Field }}{\text { type }}$ & Charge & Atom name & $\frac{\text { Force Field }}{\text { type }}$ & Charge \\
\hline $\mathrm{C} 1$ & $\underline{C R}$ & $\underline{0.18}$ & $\mathrm{H3}$ & $\underline{\mathrm{H}}$ & $\underline{0.074}$ \\
\hline $\mathrm{C} 2$ & $\mathrm{CR}$ & 0.057 & C24 & C 3 & -0.008 \\
\hline $\mathrm{C} 3$ & $\underline{\mathrm{C} R}$ & -0.365 & $\mathrm{H} 4$ & $\underline{\mathrm{H}}$ & $\underline{0.078}$ \\
\hline $\mathrm{C} 4$ & $\mathrm{CR}$ & 0.181 & $\mathrm{C25}$ & $\mathrm{C} 3$ & 0.046 \\
\hline $\mathrm{C} 5$ & $\underline{\mathrm{CR}}$ & -0.061 & C26 & $\underline{\mathrm{C}} 3$ & $\underline{-0.161}$ \\
\hline $\mathrm{C} 6$ & $\underline{\mathrm{CR}}$ & -0.058 & N3 & $\mathrm{N} 1$ & -0.417 \\
\hline 01 & $\underline{\mathrm{OR}}$ & $\underline{-0.183}$ & $\underline{\mathrm{H} 5}$ & $\underline{\mathrm{H}}$ & $\underline{0.059}$ \\
\hline $\mathrm{C} 7$ & $\underline{\mathrm{C} R}$ & 0.242 & $\underline{\mathrm{H} 6}$ & $\underline{\mathrm{H}}$ & $\underline{0.069}$ \\
\hline $\mathrm{C} 8$ & $\underline{\mathrm{CR}}$ & $\underline{0.033}$ & $\mathrm{H7}$ & $\underline{\mathrm{H}}$ & $\underline{0.094}$ \\
\hline $\mathrm{Cg}$ & $\underline{\mathrm{CR}}$ & -0.064 & $\underline{\mathrm{H} 8}$ & $\underline{\mathrm{H}}$ & $\underline{0.055}$ \\
\hline$\underline{\mathrm{C} 10}$ & $\underline{\mathrm{CR}}$ & -0.137 & $\underline{\mathrm{H} 9}$ & $\underline{\mathrm{H}}$ & $\underline{0.054}$ \\
\hline C11 & $\underline{\mathrm{C} R}$ & $\underline{0.005}$ & $\underline{\mathrm{H} 10}$ & $\underline{\mathrm{H}}$ & $\underline{0.053}$ \\
\hline $\mathrm{C} 12$ & $\underline{\mathrm{CR}}$ & $\underline{0.14}$ & H11 & $\underline{\mathrm{H}}$ & $\underline{0.029}$ \\
\hline $\mathrm{C} 13$ & $\mathrm{CR}$ & -0.344 & $\mathrm{H} 12$ & $\mathrm{H}$ & 0.038 \\
\hline N1 & $\mathrm{NR}$ & -0.002 & $\mathrm{H} 13$ & $\underline{\mathrm{H}}$ & $\underline{0.09}$ \\
\hline C14 & C 1 & $\underline{0.417}$ & $\underline{\mathrm{H} 14}$ & $\underline{\mathrm{H}}$ & $\underline{0.028}$ \\
\hline $\mathrm{C} 15$ & $\underline{\mathrm{C} 3}$ & -0.131 & $\mathrm{H} 15$ & $\underline{\mathrm{H}}$ & 0.074 \\
\hline$\underline{\mathrm{C} 16}$ & $\underline{\mathrm{C} 3}$ & $\underline{-0.137}$ & $\underline{\mathrm{H} 16}$ & $\underline{\mathrm{H}}$ & $\underline{0.1}$ \\
\hline C17 & C 3 & $\underline{-0.016}$ & $\mathrm{H} 17$ & $\mathrm{H}$ & $\underline{0.05}$ \\
\hline$\underline{\mathrm{C} 18}$ & $\underline{\mathrm{C} 3}$ & $\underline{-0.06}$ & $\underline{\mathrm{H} 18}$ & $\underline{\mathrm{H}}$ & $\underline{0.058}$ \\
\hline N2 & $\mathrm{NR}$ & 0.085 & $\mathrm{H} 19$ & $\mathrm{H}$ & 0.027 \\
\hline C19 & $\underline{\mathrm{C}} 3$ & $\underline{-0.143}$ & $\underline{\mathrm{H} 20}$ & $\underline{\mathrm{H}}$ & $\underline{0.059}$ \\
\hline $\mathrm{C} 20$ & $\underline{\mathrm{C}} 3$ & $\underline{0.016}$ & $\mathrm{H} 21$ & $\underline{\mathrm{H}}$ & $\underline{0.042}$ \\
\hline H1 & $\mathrm{H}$ & 0.211 & H22 & $\mathrm{H}$ & 0.098 \\
\hline $\mathrm{C} 21$ & C 3 & $\underline{-0.017}$ & $\mathrm{H} 23$ & $\underline{\mathrm{H}}$ & $\underline{0.048}$ \\
\hline C22 & $\underline{\mathrm{C}} 3$ & $\underline{0.018}$ & $\underline{\mathrm{H} 24}$ & $\underline{\mathrm{H}}$ & $\underline{0.043}$ \\
\hline $\mathrm{H} 2$ & $\underline{\mathrm{H}}$ & $\underline{0.209}$ & $\mathrm{H} 25$ & $\underline{\mathrm{H}}$ & $\underline{0.075}$ \\
\hline$\underline{\mathrm{C} 23}$ & $\underline{\mathrm{C} 3}$ & $\underline{-0.011}$ & $\underline{\mathrm{H} 26}$ & $\underline{\mathrm{H}}$ & $\underline{0.082}$ \\
\hline
\end{tabular}

\section{SI Table 2}

Atomic charges and DREIDING force field types of the atoms of rhodamine 800 shown in Figure $2 \underline{b}$. 


\section{Bibliography}

(1) R. Sasai; N. Iyi; T. Fujita; F.L. Arbeloa; Martinez; K. Takagi; H. Itoh. Luminescence Properties of Rhodamine 6G Intercalated in Surfactant/Clay Hybrid Thin Solid Films. Langmuir, 20, 4715 (2004)

(2) F. Marlow; M.D. McGehee; D. Zhao; B.F. Chmelka; G.D. Stucky. Doped Mesoporous Silica Fibers: A New Laser Material. Advanced Materials, 11, 632 (1999)

(3) D. Tleugabulova; Z. Zhang; Y. Chen; M.A. Brook; J.D. Brennan. Fluorescence Anisotropy in Studies of Solute Interactions with Covalently Modified Colloidal Silica Nanoparticles. Langmuir, 20, 848 (2004)

(4) L. Bahadur; P. Srivastava. Efficient photon-to-electron conversion with rhodamine 6G-sensitized nanocrystalline $\mathrm{n}$ - $\mathrm{ZnO}$ thin film electrodes in acetonitrile solution. Solar Energy Materials and Solar Cells, 79, 235 (2003)

(5) T. Ohishi. An ethoxy-silano rhodamine B derivative and its application to surface coatings on display devices. Journal of Non-Crystalline Solids, 332, 80 (2003)

(6) V. Martínez Martínez; F. López Arbeloa; J. Bañuelos Prieto; T. Arbeloa Lopez; I. López Arbeloa. Characterization of Supported Solid Thin Films of Laponite Clay. Intercalation of Rhodamine 6G Laser Dye. Langmuir, 20, 5709 (2004)

(7) A.H. Gemeay. Adsorption Characteristics and the Kinetics of the Cation Exchange of Rhodamine-6G with $\mathrm{Na}^{+}$-Montmorillonite. Journal of Colloid and Interface Science, 251, 235 (2002)

(8) J. Bujdák; N. Iyi; R. Sasai. Spectral Properties, Formation of Dye Molecular Aggregates, and Reactions in Rhodamine 6G/Layered Silicate Dispersions. The Journal of Physical Chemistry B, 108, 4470 (2004)

(9) J. Bujdák; N. Iyi. Molecular Orientation of Rhodamine Dyes on Surfaces of Layered Silicates. The Journal of Physical Chemistry B, 109, 4608 (2005)

(10) V. Martínez; S. Salleres; J. Bañuelos; F.L. Arbeloa. Application of Fluorescence with Polarized Light to Evaluate the Orientation of Dyes Adsorbed in Layered Materials. Journal of Fluorescence, 16, 233 (2006)

(11) F. del Monte; J.D. Mackenzie; D. Levy. Rhodamine fluorescent dimers adsorbed on the porous surface of silica gels. Langmuir, 16, 7377 (2000)

(12) A. Barranco; P. Groening. Fluorescent Plasma Nanocomposite Thin Films Containing Nonaggregated Rhodamine 6G Laser Dye Molecules. Langmuir, 22, 6719 (2006)

(13) R. Vogel; P. Meredith; I. Kartini; M. Harvey; J.D. Riches; A. Bishop; N. Heckenberg; M. Trau; H. Rubinsztein-Dunlop. Mesostructured Dye-Doped Titanium Dioxide for Micro-Optoelectronic Applications. ChemPhysChem, 4, 595 (2003)

(14) J.R. Sánchez-Valencia; A. Borrás; A. Barranco; V.J. Rico; J.P. Espinós; A.R. González-Elipe. Preillumination of TiO2 and Ta2O5 Photoactive Thin Films As a Tool to Tailor the Synthesis of Composite Materials. Langmuir, 24, 9460 (2008)

(15) M. Kosmulski Chemical Properties of Material Surfaces; Marcel Dekker Inc., 2001.

(16) B. O'Regan; M. Grätzel. Nature, 353, 737 (1991)

(17) A. Hagfeldt; M. Grätzel. Chemical Reviews, 95, 49 (1995)

(18) F. de Angelis; S. Fantacci; A. Selloni; M.K. Nazeeruddin; M. Grätzel. TimeDependent Density Functional Theory Investigations on the Excited States of Ru(II)-Dye- 
Sensitized $\mathrm{TiO}_{2}$ Nanoparticles: The Role of Sensitizer Protonation. Journal of the American Chemical Society, 129, 14156 (2007)

(19) S.A. Tomás; S. Stolik; R. Palomino; R. Lozada; C. Persson; I. Pepe; A. Ferreira da Silva. Influence of rhodamine $6 \mathrm{G}$ doping on the optical properties of $\mathrm{TiO}_{2}$ sol-gel films. Journal of Applied Physics, 98, 073516 (2005)

(20) R. Sasai; T. Fujita; N. Iyi; H. Itoh; K. Takagi. Aggregated Structures of Rhodamine 6G Intercalated in a Fluor-Taeniolite Thin Film. Langmuir, 18, 6578 (2002)

(21) J. Bujdák; N. Iyi. Molecular Aggregation of Rhodamine Dyes in Dispersions of Layered Silicates: Influence of Dye Molecular Structure and Silicate Properties. The Journal of Physical Chemistry $B, 110,2180$ (2006)

(22) K. Robbie; M.J. Brett. Sculptured thin films and glancing angle deposition: Growth mechanics and applications. J. Vac. Sci. Technol. A, 15, 1460 (1997)

(23) M. Predota; A.V. Bandura; P.T. Cummings; J.D. Kubicki; D.J. Wesolowski; A.A. Chialvo; M.L. Machesky. Electric Double Layer at the Rutile (110) Surface. 1. Structure of Surfaces and Interfacial Water from Molecular Dynamics by Use of ab Initio Potentials. The Journal of Physical Chemistry B, 108, 12049 (2004)

(24) A. Fortunelli; S. Monti. Simulations of Lipid Adsorption on $\mathrm{TiO}_{2}$ Surfaces in Solution. Langmuir, 24, 10145 (2008)

(25) S. Köppen; O. Bronkalla; W. Langel. Adsorption Configurations and Energies of Amino Acids on Anatase and Rutile Surfaces. The Journal of Physical Chemistry C, 112, $13600(2008)$

(26) A. Tilocca; A. Selloni. Methanol Adsorption and Reactivity on Clean and Hydroxylated Anatase(101) Surfaces. Journal of Physical Chemistry B, 108, 19314 (2004)

(27) A. Tilocca; C. Di Valentin; A. Selloni. $\mathrm{O}_{2}$ Interaction and Reactivity on a Model Hydroxylated Rutile(110) Surface. The Journal of Physical Chemistry B, 109, 20963 (2005)

(28) A.V. Bandura; J.D. Kubicki. Derivation of Force Field Parameters for $\mathrm{TiO}_{2}$ $\mathrm{H}_{2} \mathrm{O}$ Systems from ab Initio Calculations. Journal of Physical Chemistry B, 107, 11072 (2003)

(29) M. Matsui; M. Akaogi. Molecular dynamics simulation of the structural and physical properties of the four polymorphs of TiO2. Molecular Simulation, 6, 239 (1991)

(30) G. Kresse; J. Joubert. Physical Review B, 59, 1758 (1999)

(31) J. Perdew; J. Chevary; S. Vosko; K. Jackson; M. Pederson; D. Singh; C. Fiolhais. Physical Review B, 46, 6671 (1992)

(32) G. Kresse; J. Hafner. Physical Review B, 47, 558 (1993)

(33) G. Kresse; J. Furthmuller. Physical Review B, 54, 11169 (1996)

(34) G. Kresse; J. Furthmuller. Computational Materials Science, 6, 15 (1996)

(35) H.J. Monkhorst; J.D. Pack. Physical Review B, 13, 5188 (1976)

(36) S.L. Mayo; B.D. Olafson; W.A. Goddard. DREIDING: a generic force field for molecular simulations. The Journal of Physical Chemistry, 94, 8897 (1990)

(37) D.E. Williams; S.R. Cox. Nonbonded Potentials for Azahydrocarbons: the Importance of the Coulombic Interaction. Acta Cryst. B 40, 414 (1984)

(38) D.E. Williams; D.J. Houpt. Fluorine Nonbonded Potential Parameters Derived from Crystalline Perfluorocarbons. Acta Cryst. B 42, 286 (1986)

(39) U.C. Singh; P.A. Kollman. J. Comp. Chem., 5, 129 (1984)

(40) B.H. Besler; K.M. Merz Jr; P.A. Kollman. J. Comp. Chem., 11, 431 (1990)

(41) M.J. Frisch; G.W. Trucks; H.B. Schlegel; G.E. Scuseria; M.A. Robb; J.R. Cheeseman; J.A.M. Jr.; T. Vreven; K.N. Kudin; J.C. Burant; J.M. Millam; S.S. Iyengar; J. Tomasi; V. Barone; B. Mennucci; M. Cossi; G. Scalmani; N. Rega; G.A. Petersson; H. 
Nakatsuji; M. Hada; M. Ehara; K. Toyota; R. Fukuda; J. Hasegawa; M. Ishida; T. Nakajima; Y. Honda; O. Kitao; H. Nakai; M. Klene; X. Li; J.E. Knox; H.P. Hratchian; J.B. Cross; V. Bakken; C. Adamo; J. Jaramillo; R. Gomperts; R.E. Stratmann; O. Yazyev; A.J. Austin; R. Cammi; C. Pomelli; J.W. Ochterski; P.Y. Ayala; K. Morokuma; G.A. Voth; P. Salvador; J.J. Dannenberg; V.G. Zakrzewski; S. Dapprich; A.D. Daniels; M.C. Strain; O. Farkas; D.K. Malick; A.D. Rabuck; K. Raghavachari; J.B. Foresman; J.V. Ortiz; Q. Cui; A.G. Baboul; S. Clifford; J. Cioslowski; B.B. Stefanov; G. Liu; A. Liashenko; P. Piskorz; I. Komaromi; R.L. Martin; D.J. Fox; T. Keith; M.A. Al-Laham; C.Y. Peng; A. Nanayakkara; M. Challacombe; P.M.W. Gill; B. Johnson; W. Chen; M.W. Wong; C. Gonzalez; G. J. A. Pople, Inc., Wallingford CT. Gaussian 03, 2004.

(42) A.D. Becke. J. Chem. Phys., 98, 5648 (1993)

(43) P. Capková; P. Malý; M. Pospísil; Z. Klika; H. Weissmannová; Z. Weiss. Effect of surface and interlayer structure on the fluorescence of rhodamine Bmontmorillonite: modeling and experiment. Journal of Colloid and Interface Science, 277, 128 (2004)

(44) J.D. Gale. GULP: A computer program for the symmetry-adapted simulation of solids. Journal of the Chemical Society, Faraday Transactions, 93, 629 (1997)

(45) Z. Klika; H. Weissmannová; P. Capková; M. Pospísil. The rhodamine B intercalation of montmorillonite. Journal of Colloid and Interface Science, 275, 243 (2004)

(46) F. López Arbeloa; R. Chaudhuri; T. Arbeloa López; I. López Arbeloa. Aggregation of Rhodamine 3B Adsorbed in Wyoming Montmorillonite Aqueous Suspensions. Journal of Colloid and Interface Science, 246, 281 (2002)

(47) V. Martínez Martínez; F. López Arbeloa; J. Bañuelos Prieto; T. Arbeloa López; I. López Arbeloa. Characterization of Rhodamine 6G Aggregates Intercalated in Solid Thin Films of Laponite Clay. 1. Absorption Spectroscopy. The Journal of Physical Chemistry B, 108, 20030 (2004) 
Page 4: [1] Deleted saidhg 3/27/2009 10:26:00 AM

\section{Experimental details and materials}

Composite $\mathrm{R} 6 \mathrm{G} / \mathrm{TiO}_{2}$ and $\mathrm{R} 800 / \mathrm{TiO}_{2}$ thin films were prepared by using porous $\mathrm{TiO}_{2}$ thin films as host materials. For this purpose, transparent and amorphous $\mathrm{TiO}_{2}$ were prepared by Glacing Angle Physical Vapor Deposition (GAPVD) at room temperature on quartz and silicon substrates. Evaporation was carried out in an electron bombardment evaporator by using $\mathrm{TiO}_{2}$ pellets as target material. Stoichiometric thin films of $\mathrm{TiO}_{2}$ were obtained by performing the evaporation in $10^{-4}$ torrs of $\mathrm{O}_{2}$. The evaporation was carried out by placing the substrates at a glancing angle of $70^{\circ}$ with respect to the evaporator source. This geometry produces films with a tilted columnar microstructure with a high porosity ${ }^{19-21}$. The films with a thickness around $400 \mathrm{~nm}$ were prepared by this method. In the present case the porosity of the films was estimated to be $35 \%$ of the total volume of the films, with a $70 \%$ of pores consisting of mesopores. A full account of the characteristics of these films can be found in a previous publication ${ }^{14}$.

The microstructure of the $\mathrm{TiO}_{2}$ thin films deposited on a silicon wafer was examined by Field Emission Scanning Electron Microscopy (FESEM) in a Hitachi S5200 microscope. Cross sectional views were obtained by cleaving the silicon substrates.

UV-visible absorption spectra in transmission mode were recorded with a PerkinElmer Lambda 12 spectrometer for the thin films deposited on quartz plates. Although the absorbance is the typical magnitude used for presenting UV-vis absorption spectra of dyes in liquid solutions, we present here some spectra as the percentage of transmitted light. We have made this choice because this is the usual way of presenting these data when using optical thin films ${ }^{22}$. 
A chloride salt of R6G and R800 dye molecules was used for the experiments. The salts were supplied by ALDRICH and used without further purification. In solution, the cationic R6G or $\mathrm{R} 800$ bear a positive charge, a feature that is essential for the incorporation of the dye into the $\mathrm{TiO}_{2}$ thin films.

A $10^{-4} \mathrm{M}$ solutions of the dyes in water at controlled values of $\mathrm{pH}$ were used for the infiltration experiments. The $\mathrm{pH}$ of the solution was controlled between 1.9 and 6.6 by adding giving amounts of $\mathrm{HCl}$ or $\mathrm{NaOH}$. The $\mathrm{TiO}_{2}$ films were immersed in one of these solutions and maintained there for $10 \mathrm{~min}$. The samples were then removed from the solution and washed with water at the same $\mathrm{pH}$ than that of the dye solutions. In general, the intensity of the colour of the films changed with the $\mathrm{pH}$ of the solution, a feature that suggests the dependence between this parameter and the ability to incorporate the dye molecules into the films.

Figure 1 shows a series of UV-vis transmission spectra recorded for $\mathrm{TiO}_{2}$ thin films containing different concentrations of R6G and R800, as indicated in Table 1. The spectra are characterized by the presence of a series of bands typical of the R6G dye molecules (i.e., bands centred at $\sim 520 \mathrm{~nm}$ ) and R800 (i.e., bands centred at $\sim 650 \mathrm{~nm})^{14}$ superimposed on the typical oscillations due to interference phenomena between a substrate and a transparent layer of different refraction index ${ }^{14}$. For the purposes of the present work, the most important result is the dependence of the intensity of the features attributed to the two dye molecules and the $\mathrm{pH}$ of the solution used for the preparation of the films. Thus, it is observed that the intensity of the R6G features are strongly dependent on the $\mathrm{pH}$, increasing with this parameter. By contrast, $\mathrm{R} 800$ is little or no sensitive to this parameter and the intensity of its spectral features remains almost 
constant for all the pHs. This different behaviour suggests that these two molecular cations interact differently with the surface of $\mathrm{TiO}_{2}$ and that, particularly for the $\mathrm{R} 800$, the state of charge on the $\mathrm{TiO}_{2}$ does not affect significantly the adsorption of this molecule.

\section{3}

Page 22: [2] Deleted saidhg 3/27/2009 2:02:00 PM

\begin{tabular}{|c|c|c|c|c|c|}
\hline Atom name & $\begin{array}{l}\text { Force Field } \\
\text { type }\end{array}$ & Charge & Atom name & $\begin{array}{c}\text { Force Field } \\
\text { type }\end{array}$ & Charge \\
\hline C1 & C_R & 0,48 & 03 & O_2 & -0.46 \\
\hline $\mathrm{C} 2$ & C_R & -0.139 & C27 & C_3 & 0.346 \\
\hline C3 & C_R & -0.287 & $\mathrm{C} 28$ & C_3 & -0.25 \\
\hline C4 & C_R & 0.114 & H1 & $\mathrm{H}$ & 0.173 \\
\hline C5 & C_R & 0.287 & $\mathrm{H} 2$ & $\mathrm{H}_{-}$ & 0.231 \\
\hline C6 & C_R & -0.438 & H3 & $\mathrm{H}$ & 0.238 \\
\hline 01 & O_R & -0.385 & $\mathrm{H} 4$ & $\mathrm{H}$ & 0.17 \\
\hline C7 & C_R & 0.487 & H5 & $\mathrm{H}$ & 0.365 \\
\hline C8 & C_R & -0.136 & $\mathrm{H} 6$ & $\mathrm{H}$ & 0.139 \\
\hline C9 & C_R & 0.08 & $\mathrm{H7}$ & $\mathrm{H}$ & 0.15 \\
\hline $\mathrm{C} 10$ & C_R & -0.46 & $\mathrm{H} 8$ & $\mathrm{H}_{-}$ & 0.155 \\
\hline C11 & C_R & 0.31 & $\mathrm{H9}$ & $\mathrm{H}_{-}$ & 0.148 \\
\hline C12 & C_R & 0.106 & $\mathrm{H} 10$ & $\mathrm{H}$ & 0.089 \\
\hline C13 & C_R & -0.285 & $\mathrm{H} 11$ & $\mathrm{H}$ & 0.123 \\
\hline N1 & N_R & -0.534 & $\mathrm{H} 12$ & $\mathrm{H}$ & 0.083 \\
\hline C14 & C_R & 0.428 & H13 & $\mathrm{H}$ & 0.125 \\
\hline C15 & C_R & -0.298 & H14 & $\mathrm{H}$ & 0.093 \\
\hline C16 & C_R & -0.058 & H15 & $\mathrm{H}_{-}$ & 0.089 \\
\hline C17 & C_R & -0.161 & H16 & $\mathrm{H}$ & 0.045 \\
\hline C18 & C_R & -0.083 & $\mathrm{H} 17$ & $\mathrm{H}$ & 0.054 \\
\hline C19 & C_R & -0.302 & H18 & $\mathrm{H}$ & 0.079 \\
\hline $\mathrm{C2O}$ & C_3 & -0.286 & H19 & $\mathrm{H}$ & 0.087 \\
\hline $\mathrm{C} 21$ & C_3 & -0.303 & $\mathrm{H} 2 \mathrm{O}$ & $\mathrm{H}$ & 0.357 \\
\hline $\mathrm{C} 22$ & C_3 & 0.166 & $\mathrm{H} 21$ & $\mathrm{H}_{-}$ & 0.063 \\
\hline $\mathrm{C} 23$ & C_3 & -0.232 & $\mathrm{H} 22$ & $\mathrm{H}_{-}$ & 0.041 \\
\hline N2 & N_R & -0.521 & $\mathrm{H} 23$ & $\mathrm{H}$ & 0.033 \\
\hline C24 & C_3 & 0.205 & $\mathrm{H} 24$ & $\mathrm{H}$ & 0.079 \\
\hline C25 & C_3 & -0.242 & $\mathrm{H} 25$ & $\mathrm{H}$ & 0.061 \\
\hline
\end{tabular}




\begin{tabular}{|c|c|c|c|c|c|}
\hline C26 & C_2 & 0.784 & H26 & $H_{-}$ & 0.088 \\
\hline O2 & O_1 & -0.532 & H27 & $H_{-}$ & -0.001 \\
\hline O3 & O_2 & -0.46 & H28 & $H_{-}$ & 0.002 \\
\hline C27 & C_3 & 0.346 & H29 & $H_{-}$ & 0.071 \\
\hline C28 & C_3 & -0.25 & H30 & $H_{-}$ & 0.084 \\
\hline H1 & H_ & 0.173 & H31 & $H_{-}$ & 0.085 \\
\hline
\end{tabular}

\section{Table 3}

Atomic charges and DREIDING force field types of the atoms of rhodamine 6G shown in Figure 3a.

\begin{tabular}{|c|c|c|c|c|c|}
\hline Atom name & $\begin{array}{c}\text { Force Field } \\
\text { type }\end{array}$ & Charge & Atom name & $\begin{array}{l}\text { Force Field } \\
\text { type }\end{array}$ & Charge \\
\hline C1 & C_R & 0.18 & H3 & $\mathrm{H}_{-}$ & 0.074 \\
\hline $\mathrm{C} 2$ & C_R & 0.057 & $\mathrm{C} 24$ & C_3 & -0.008 \\
\hline C3 & C_R & -0.365 & $\mathrm{H} 4$ & $\mathrm{H}_{-}$ & 0.078 \\
\hline C4 & C_R & 0.181 & C25 & C_3 & 0.046 \\
\hline C5 & C_R & -0.061 & $\mathrm{C} 26$ & C_3 & -0.161 \\
\hline $\mathrm{C} 6$ & C_R & -0.058 & N3 & N_1 & -0.417 \\
\hline 01 & O_R & -0.183 & $\mathrm{H} 5$ & $\mathrm{H}$ & 0.059 \\
\hline $\mathrm{C7}$ & C_R & 0.242 & H6 & $\mathrm{H}$ & 0.069 \\
\hline C8 & C_R & 0.033 & $\mathrm{H} 7$ & $\mathrm{H}$ & 0.094 \\
\hline C9 & C_R & -0.064 & $\mathrm{H} 8$ & $\mathrm{H}$ & 0.055 \\
\hline C10 & C_R & -0.137 & $\mathrm{H9}$ & $\mathrm{H}$ & 0.054 \\
\hline C11 & C_R & 0.005 & $\mathrm{H} 10$ & $\mathrm{H}$ & 0.053 \\
\hline C12 & C_R & 0.14 & H11 & $\mathrm{H}$ & 0.029 \\
\hline C13 & C_R & -0.344 & H12 & $\mathrm{H}$ & 0.038 \\
\hline N1 & N_R & -0.002 & H13 & $\mathrm{H}$ & 0.09 \\
\hline C14 & C_1 & 0.417 & H14 & $\mathrm{H}$ & 0.028 \\
\hline C15 & C_3 & -0.131 & H15 & $\mathrm{H}$ & 0.074 \\
\hline C16 & C_3 & -0.137 & $\mathrm{H} 16$ & $\mathrm{H}$ & 0.1 \\
\hline C17 & C_3 & -0.016 & $\mathrm{H} 17$ & $\mathrm{H}_{-}$ & 0.05 \\
\hline C18 & C_3 & -0.06 & H18 & $\mathrm{H}$ & 0.058 \\
\hline N2 & N_R & 0.085 & H19 & $\mathrm{H}$ & 0.027 \\
\hline C19 & C_3 & -0.143 & $\mathrm{H} 2 \mathrm{O}$ & $\mathrm{H}$ & 0.059 \\
\hline $\mathrm{C} 20$ & C_3 & 0.016 & $\mathrm{H} 21$ & $\mathrm{H}$ & 0.042 \\
\hline $\mathrm{H} 1$ & $\mathrm{H}_{-}$ & 0.211 & $\mathrm{H} 22$ & $\mathrm{H}$ & 0.098 \\
\hline $\mathrm{C} 21$ & C_3 & -0.017 & $\mathrm{H} 23$ & $\mathrm{H}$ & 0.048 \\
\hline $\mathrm{C} 22$ & C_3 & 0.018 & $\mathrm{H} 24$ & $\mathrm{H}$ & 0.043 \\
\hline $\mathrm{H} 2$ & $\mathrm{H}$ & 0.209 & $\mathrm{H} 25$ & $\mathrm{H}$ & 0.075 \\
\hline $\mathrm{C} 23$ & C_3 & -0.011 & H26 & $\mathrm{H}_{-}$ & 0.082 \\
\hline
\end{tabular}




\section{Table 4}

Atomic charges and DREIDING force field types of the atoms of rhodamine 800 shown in Figure 3b.

Page Break 